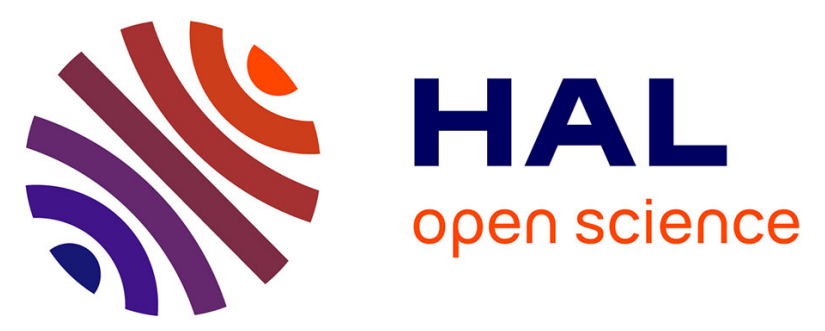

\title{
Mesoporous Single-Atom-Doped Graphene-Carbon Nanotube Hybrid: Synthesis and Tunable Electrocatalytic Activity for Oxygen Evolution and Reduction Reactions
}

Mohammad Tavakkoli, Emmanuel Flahaut, Pekka Peljo, Jani Sainio, Fatemeh Davodi, Egor V. Lobiak, Kimmo Mustonen, Esko I. Kauppinen

\section{To cite this version:}

Mohammad Tavakkoli, Emmanuel Flahaut, Pekka Peljo, Jani Sainio, Fatemeh Davodi, et al.. Mesoporous Single-Atom-Doped Graphene-Carbon Nanotube Hybrid: Synthesis and Tunable Electrocatalytic Activity for Oxygen Evolution and Reduction Reactions. ACS Catalysis, 2020, 10 (8), pp.46474658. 10.1021/acscatal.0c00352 . hal-02864773

\section{HAL Id: hal-02864773 https://hal.science/hal-02864773}

Submitted on 11 Jun 2020

HAL is a multi-disciplinary open access archive for the deposit and dissemination of scientific research documents, whether they are published or not. The documents may come from teaching and research institutions in France or abroad, or from public or private research centers.
L'archive ouverte pluridisciplinaire HAL, est destinée au dépôt et à la diffusion de documents scientifiques de niveau recherche, publiés ou non, émanant des établissements d'enseignement et de recherche français ou étrangers, des laboratoires publics ou privés. 


\section{OATAO \\ Open Archive Toulouse Archive Ouverte}

\section{Open Archive Toulouse Archive Ouverte (OATAO)}

OATAO is an open access repository that collects the work of Toulouse researchers and makes it freely available over the web where possible

This is a Publisher's version published in: http://oatao.univ-toulouse.fr/26099

Official URL: https://doi.org/10.1021/acscatal.0c00352

\section{To cite this version:}

Tavakkoli, Mohammad and Flahaut, Emmanuel $\stackrel{\supset}{ }$ and Peljo, Pekka and Sainio, Jani and Davodi, Fatemeh and Lobiak, Egor V. and Mustonen, Kimmo and Kauppinen, Esko I. Mesoporous Single-Atom-Doped Graphene-Carbon Nanotube Hybrid: Synthesis and Tunable Electrocatalytic Activity for Oxygen Evolution and Reduction Reactions. (2020) ACS Catalysis, 10 (8). 4647-4658. ISSN 2155-5435

Any correspondence concerning this service should be sent to the repository administrator: tech-oatao@listes-diff.inp-toulouse.fr 


\title{
Mesoporous Single-Atom-Doped Graphene-Carbon Nanotube Hybrid: Synthesis and Tunable Electrocatalytic Activity for Oxygen Evolution and Reduction Reactions
}

\author{
Mohammad Tavakkoli,* Emmanuel Flahaut, Pekka Peljo, Jani Sainio, Fatemeh Davodi, Egor V. Lobiak, \\ Kimmo Mustonen, and Esko I. Kauppinen
}

Cite This: ACS Catal. 2020, 10, 4647-4658

Read Online

ABSTRACT: Mesoporous heteroatom-doped carbon-based nanomaterials are very promising as catalysts for electrochemical energy conversion and storage. We have developed a one-step catalytic chemical vapor deposition method to grow a highly graphitized graphene nanoflake (GF)-carbon nanotube (CNT) hybrid material doped simultaneously with single atoms of $\mathrm{N}, \mathrm{Co}$, and $\mathrm{Mo}(\mathrm{N}-\mathrm{Co}-\mathrm{Mo}-$ $\mathrm{GF} / \mathrm{CNT}$ ). This high-surface-area material has a mesoporous structure, which facilitates oxygen mass transfer within the catalyst film, and exhibits a high electrocatalytic activity and stability in oxygen reduction and evolution reactions (ORR and OER) in alkaline media. We have shown that in this metal (M)-N-C

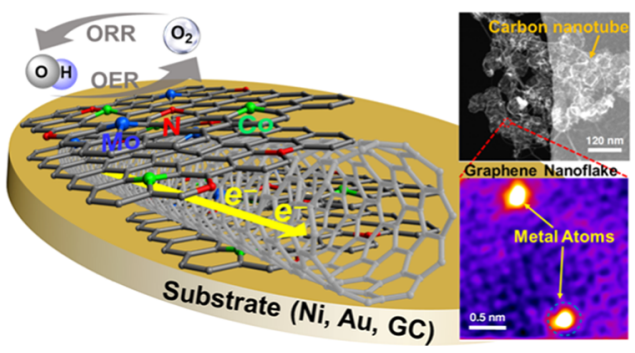
catalyst, $\mathrm{M}(\mathrm{Co}, \mathrm{Mo})-\mathrm{C}$ centers are the main sites responsible for $\mathrm{OER}$, while, for

ORR, both $\mathrm{M}$ and $\mathrm{N}-\mathrm{C}$ centers synergistically serve as the active sites. We systematically investigated tuning of the ORR and OER activity of the porous catalyst depending on the choice of the underlying substrate. The ORR kinetic current and OER activity for $\mathrm{N}-\mathrm{Co}-\mathrm{Mo}-\mathrm{GF} / \mathrm{CNT}$ were significantly enhanced when the catalyst was deposited onto a Ni substrate, resulting in an advanced electrocatalytic performance compared to the best bifunctional ORR/OER catalysts reported so far. Using a developed scanning electrochemical microscopy analysis method, we demonstrated that the higher OER reactivity on Ni was attributable to the formation of underlying catalyst/Ni interfacial sites, which are accessible due to the porous, electrolyte-permeable structure of the catalyst.

KEYWORDS: single-atom electrocatalysis, heteroatom doping, graphene-carbon nanotube hybrid, mesoporous electrocatalyst, oxygen reduction/evolution reaction, substrate effect, scanning electrochemical microscopy

\section{INTRODUCTION}

The need for low-cost electrocatalysts based on earth-abundant materials, rather than critical noble metals, such as $\mathrm{Pt}, \mathrm{Ru}$, and Ir, for catalyzing oxygen reduction reaction (ORR) and oxygen evolution reaction (OER) has motivated a large body of research. ORR and OER are the most important electrochemical reactions that limit the efficiencies of fuel cells, water electrolyzers, and metal-air batteries. An ORR or OER electrode comprises three main components: (i) an electrocatalyst film composed of active sites for catalysis, (ii) a catalyst support, which is typically made of high-surface-area and porous carbon-based materials that can enhance the number of active sites on the surface and improve the conductivity of the catalyst, and (iii) a conductive substrate on which the electrocatalyst (or catalyst/support) is deposited. All three components require a rational design for the production of advanced electrodes for electrochemical energy storage and conversion devices.

Among various nonprecious electrocatalysts, nitrogen (N)doped carbon materials $(\mathrm{N}-\mathrm{C})$ have recently evolved into metal-free ORR and OER catalysts. ${ }^{1,2}$ The catalytic activity of
$\mathrm{N}-\mathrm{C}$ electrocatalysts for $\mathrm{ORR}^{3-6}$ and $\mathrm{OER}^{7}$ can be further improved by codoping with transition metals $(\mathrm{M}-\mathrm{N}-\mathrm{C}$ catalysts). $\mathrm{M}-\mathrm{N}-\mathrm{C}$ catalysts are generally synthesized by pyrolysis of a mixture of nitrogen-containing chemicals, transition metal inorganic salts, and carbon-based supporting materials. ${ }^{8}$ Carbon-supporting materials for fuel cell electrodes should possess high porosity, high conductivity, a large surface area, and high electrochemical stability. ${ }^{4,9,10}$ Porous materials facilitate electrolytic mass transport through the electrode and increase accessibility to the active sites. ${ }^{2,3}$ For oxygen mass transfer, mesopores (pore size 2-50 nm) are superior to micropores (pore size $<2 \mathrm{~nm}$ ). ${ }^{11,12}$ Mesoporous structures enhance the portion of electrochemically available active sites, ${ }^{3}$ and they have been reported to be promising porous

Received: January 21, 2020

Revised: $\quad$ March 9, 2020

Published: March 20, 2020 
electrodes, ${ }^{12-14}$ which can activate extra active sites within the pores and enhance the electrocatalytic activity for ORR. Recently, N-doped mesoporous carbons containing transition metals have been reported to be promising bifunctional electrocatalysts for ORR/OER ${ }^{15}$ and water electrolysis. ${ }^{16}$ Carbon black has been widely utilized as the catalyst support due to its high availability and low cost; it nevertheless contains a high number of micropores, which hinder oxygen transport in the electrocatalyst and reduce the accessibility of active sites. $^{4,10}$ Carbon black also contains an abundance of dangling bonds and defects, which can easily form surface oxides, resulting in corrosion under electrochemical oxidation. ${ }^{17}$ In contrast, catalyst supports that consist of a highly graphitized carbon structure, such as carbon nanotubes (CNTs) and graphene, are reported to be more stable. ${ }^{10,17,18}$ CNTs and graphene have high conductivity and can be doped by heteroatoms, which differ from carbon in their electronegativity. The heteroatom doping of graphitic carbon nanomaterials, regardless of whether the dopant has a lower (as B, P, S, and transition metals) or higher (as N) electronegativity than that of carbon, can polarize adjacent carbon atoms, change the electronic properties of carbon skeletons, ${ }^{2,19}$ and improve the catalytic activity of carbon-based electrocatalysts for various electrochemical reactions, including $\mathrm{ORR}^{20-22}$ and OER. ${ }^{23,24}$ Therefore, designing high-surfacearea mesoporous $\mathrm{M}-\mathrm{N}-\mathrm{C}$ electrocatalysts using $\mathrm{CNT}$ and graphene supports is a promising route to producing highly active and robust materials for catalyzing ORR and OER.

Graphene-CNT hybrid nanomaterials have demonstrated promising performance in various applications. ${ }^{25-31}$ The simultaneous growth of graphene and CNT has, however, rarely been reported, ${ }^{26,27,32-34}$ but typically resulted in graphitic structures with a relatively high number of defects. In graphene-CNT hybrid films, the CNTs form a conductive framework to which the graphene flakes adhere, significantly improving overall conductivity. ${ }^{26,32}$ Due to an increase in tunneling efficiency, the conductivity of a graphene-CNT hybrid can surpass that of a CNT film. ${ }^{35}$ Here, we report a synthesis method that produces a high-quality graphene-CNT hybrid in which the graphene flakes are doped with $\mathrm{N}, \mathrm{Co}$, and Mo heteroatoms for enhanced electrocatalytic performance.

Substrates over which electrocatalysts are deposited play an important role in defining electrocatalytic activity. The substrate can modify the surface morphology, porosity, electronic structure, and conductivity of electrocatalysts. ${ }^{36,37}$ For ORR, the role of the substrate has not been well studied in alkaline media. However, experimental investigations have shown that the OER electrocatalytic activities of manganese, ${ }^{38,39}$ cobalt, $^{40}$ and $\mathrm{Ni}$-based ${ }^{41}$ oxides, as well as $\mathrm{Fe}$ (oxy)hydroxide, ${ }^{42} \mathrm{NiCeO}_{x}{ }^{43}$ and amorphous $\mathrm{Co}(\mathrm{OH})_{2}{ }^{44}$ in alkaline media are dramatically improved using an $\mathrm{AuO}_{x} / \mathrm{Au}$ substrate instead of commonly used glassy carbon (GC). The $\mathrm{Au}$ substrate can potentially diffuse into the electrocatalyst film. ${ }^{43}$ An electrocatalyst possessing a porous, electrolytepermeable structure furthermore provides access to underlying active sites, ${ }^{42,45}$ allowing the formation of metal oxide-gold interfacial sites that catalyze the OER at lower overpotentials than metal oxide sites. ${ }^{43} \mathrm{Ni}$ foam has also been widely used in recent years for the enhancement of the OER activity of various electrocatalysts. ${ }^{46}$ However, $\mathrm{Ni}$ foam offers a large active surface area and a highly continuous porous threedimensional (3D) network enhancing accessibility to the active sites and thus electrocatalytic activity. This makes a systematic comparison with other substrates difficult, as it is unclear how much activity is enhanced by the formation of catalyst/ substrate interfacial active sites, relative to the influence of the structure and morphology of the substrate.

Here, we introduce a facile and scalable one-step synthesis method for the production of a novel electrocatalyst composed of few-layer graphene nanoflakes (GFs) and CNTs doped with $\mathrm{N}$, Co, and Mo heteroatoms (N-Co-Mo-GF/CNT). In catalysis science, the new field of single-atom catalysts (SACs) with isolated metal atoms dispersed on solid supports has attracted wide research attention because of the maximum atom-utilization efficiency and unique properties of SACs. ${ }^{47}$ Among SACs, those with carbon-based ${ }^{48}$ and particularly with graphene or graphene-like ${ }^{49}$ supports are widely investigated catalysts because of the extraordinary physicochemical properties of such supports. However, owing to the high surface energy of single atoms, immobilization of atomic metal centers on the support for the fabrication of SACs has been challenging. ${ }^{47}$ Here, in contrast to other synthetic strategies for SACs, ${ }^{47-49}$ the SAC is produced during the synthesis of the carbon support (GF/CNT), providing a facile one-step synthesis process for the fabrication of high-performance SACs without any extra cost arising from the immobilization process of the single-atom metals on the support. This highsurface-area mesoporous catalyst shows high ORR and OER activities in alkaline media. Furthermore, we have systematically investigated the role of $\mathrm{Ni}, \mathrm{Au}$, and GC flat disk substrates on the ORR and OER catalytic activities of a high-performance mesoporous catalyst $(\mathrm{N}-\mathrm{Co}-\mathrm{Mo}-\mathrm{GF} / \mathrm{CNT})$ in comparison to well-established ORR and OER catalysts such as $\mathrm{Pt} / \mathrm{C}$ and $\mathrm{RuO}_{2}$, respectively. Our study of substrate effects on the OER and ORR catalytic activity of porous materials establishes a basis for the rational design of electrodes with optimized activity and provides guidelines for future studies.

\section{RESULTS AND DISCUSSION}

2.1. Synthesis of Catalyst Materials. $\mathrm{N}-\mathrm{Co}-\mathrm{Mo}-\mathrm{GF} /$ CNT was synthesized by modifying a catalytic chemical vapor deposition (CCVD) method ${ }^{50}$ that was initially developed for the scalable synthesis of CNTs. The CCVD synthesis of the CNTs is a chemical vapor deposition (CVD) process in which the carbon precursor molecules are catalytically decomposed at high temperatures on the surface of a metallic support that acts as the catalyst for the growth of CNTs. The mesoporous NCo-Mo-GF/CNT catalyst was prepared using a CCVD synthesis reactor as depicted in Figure 1. The synthesis process has been optimized to grow a GF/CNT hybrid via a one-step synthesis process. Briefly, $\mathrm{Mg}_{0.99}\left(\mathrm{Co}_{1-x} \mathrm{Mo}_{x}\right)_{0.01} \mathrm{O}(x \sim 0.25)$ was used as the catalyst to synthesize graphitic carbon nanomaterials. This catalyst was developed previously for the synthesis of double-walled CNTs. ${ }^{50,51}$ Using this catalyst, the growth of crumpled graphene structures has been also observed during the CCVD synthesis of the CNTs, ${ }^{51}$ probably by the direct catalytic decomposition of $\mathrm{CH}_{4}$ on $\mathrm{MgO}$ oxide. $^{51,52}$ In this work, the growth conditions were optimized to grow a graphene-CNT hybrid material rather than CNTs or graphene layers. The catalyst was prepared by combustion synthesis of a stoichiometric mixture of $\left(\mathrm{NH}_{4}\right) 6 \mathrm{Mo}_{7} \mathrm{O}_{24} \cdot 4 \mathrm{H}_{2} \mathrm{O}$, magnesium and cobalt nitrates, and citric acid fuel as explained in refs 50 and 53. The catalyst powder was then placed in a furnace under a flow of $205 \mathrm{sccm} \mathrm{H}_{2}$ and $45 \mathrm{sccm} \mathrm{CH}_{4}$. The furnace temperature was increased from ambient temperature to $1000{ }^{\circ} \mathrm{C}$, kept there for $6 \mathrm{~min}$, and then slowly decreased to 


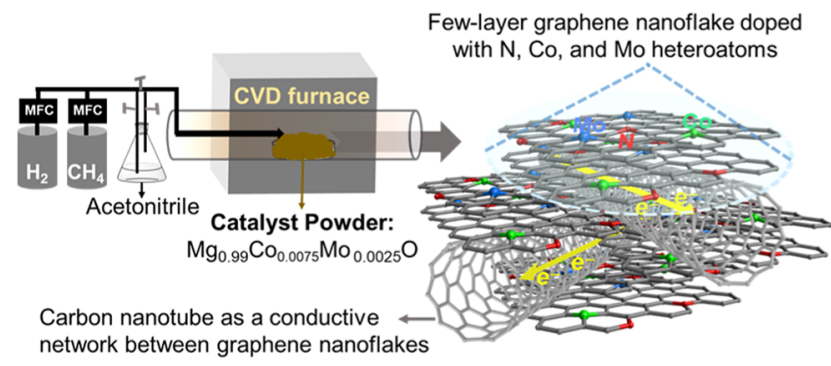

Figure 1. Scheme of the synthesis reactor used for the growth of the $\mathrm{N}-\mathrm{Co}-\mathrm{Mo}-\mathrm{GC} / \mathrm{CNT}$ and $\mathrm{Co}-\mathrm{Mo}-\mathrm{GC} / \mathrm{CNT}$ materials (MFC is an abbreviation for mass flow controller). The schematic illustration of the $\mathrm{N}-\mathrm{Co}-\mathrm{Mo}-\mathrm{GC} / \mathrm{CNT}$ sample is based on high-resolution scanning transmission electron microscopy (STEM) images and electron energy loss spectroscopy (EELS) analysis.

room temperature. The heating and cooling were performed at a rate of $5{ }^{\circ} \mathrm{C} \mathrm{min}^{-1}$. For the nitrogen-doped material, acetonitrile was introduced into the reactor by bubbling the feedstock of hydrogen and methane (total flow rate $=250$ sccm) through an impinger containing anhydrous acetonitrile for $6 \mathrm{~min}$ with the furnace temperature at $1000{ }^{\circ} \mathrm{C}$ so that $\sim 1$ $\mathrm{mL}$ acetonitrile was utilized in this process. The time during which the $\mathrm{N}$ source was introduced into the synthesis reactor was extremely short in comparison to the overall growth time of the material. Hence, the sample synthesized without $\mathrm{N}$ heteroatoms (denoted the Co-Mo-GF/CNT sample) would likely have a similar structure to that synthesized with $\mathrm{N}$ dopants, except for the $\mathrm{N}$ heteroatoms in part of the graphitic carbon network.

After cooling to room temperature, the sample was processed with an aqueous solution of $\mathrm{HCl}$ to dissolve the remaining catalyst powder and unprotected catalytic nanoparticles. The sample was washed with deionized water until a neutral $\mathrm{pH}$ was obtained. After washing, the wet sample was frozen and then dried by lyophilization. During this process, only those metallic atoms/nanoparticles that were firmly embedded in the graphitic carbon network were protected against dissolution in the acid. After this step, inductively coupled plasma atomic emission spectroscopy (ICP-AES) revealed 4.96 and 1.65 wt \% for Co and Mo, respectively, in the $\mathrm{N}-\mathrm{Co}-\mathrm{Mo}-\mathrm{GF} / \mathrm{CNT}$ hybrid material (see details of the elemental analysis in the Supporting Information).

The resulting material was dispersed in ethanol $(5 \mathrm{mg}$ $\mathrm{mL}^{-1}$ ) using ultrasound sonication for $1 \mathrm{~h}$, followed by magnetic stirring for 3 days, so that a homogeneous ink was formed. This ink was used for the material characterizations and the electrochemical measurements.

2.2. Characterization of the Synthesized Material. 2.2.1. Atomic Resolution Electron Microscopy Characterization. High-resolution transmission electron microscopy (HR-TEM) images of the N-Co-Mo-GF/CNT hybrid material are shown in Figure $2 a, b$, where the presence of 50-70 nm GFs is visible. Scanning TEM (STEM) was also employed (Figure 2c-h), in which an angstrom-sized $60 \mathrm{keV}$ electron probe was raster-scanned over the sample, and images were recorded with high- or medium-angle annular dark-field (HAADF and MAADF) detectors. Electron energy loss spectroscopy (EELS) with single-atom precision was also performed. The signals from the detectors and EELS can be obtained simultaneously, allowing direct correlation of images and spectroscopic data. In MAADF and especially HAADF imaging, the contrast of the image is highly sensitive to the atomic number or the mass of nuclei ( $Z$-contrast images). $Z$ contrast allows individual heavy atoms and small metallic nanoparticles to be distinguished from the low- $Z$ carbon support based on their brightness. ${ }^{54-58}$ Here, both annular detectors were used, and elemental identification at the atomic resolution was conducted by EELS as has been previously done for heteroatom-doped graphene and CNTs. ${ }^{54,55,59,60}$ Figure $2 \mathrm{c}, \mathrm{d}$ demonstrates how the CNTs bridge the graphene nanoflakes, leading to the expected improvement in the material conductivity. Metallic Co and Mo atoms were not detected in the monolayer graphene (Figure 2e,f), whereas $\mathrm{N}$ was identified directly from the STEM image, for which the corresponding EELS point spectrum is shown in Figure S1. Figure if demonstrates the presence of pentagon and heptagon rings in the hexagonal crystalline structure leading to strainrelated corrugation in the structure of GFs. In contrast to monolayer GFs, individual metal atoms were identified in multilayers, as is evident in Figures S2 and 2g,h. Figure S2 shows example STEM images of Co and Mo heteroatoms with corresponding EELS maps. In a binary collision with a $60 \mathrm{keV}$

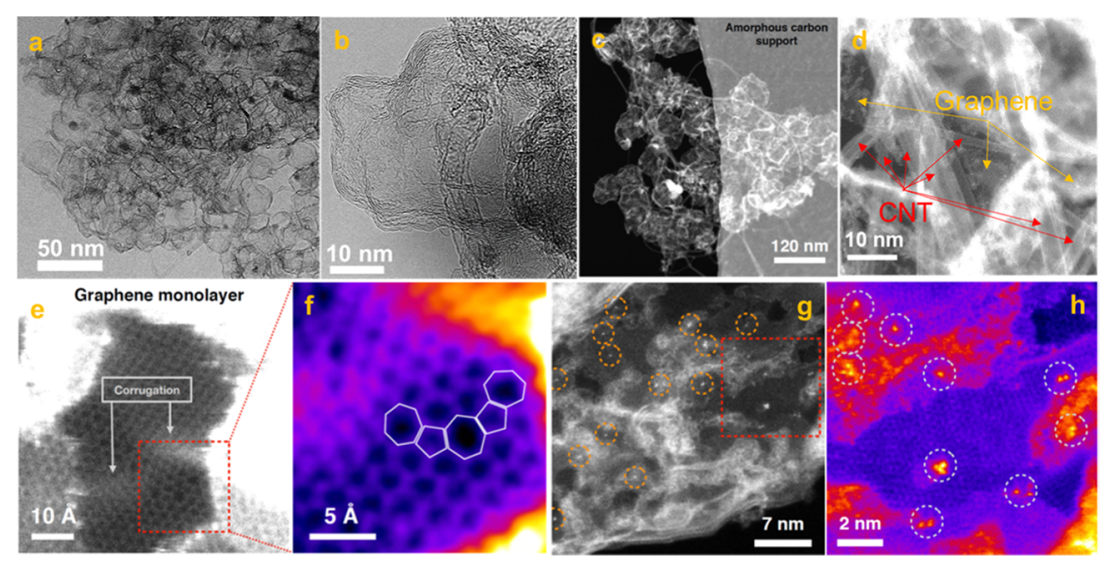

Figure 2. (a, b) HR-TEM and (c-h) STEM images of N-Co-Mo-GF/CNT. (a) TEM image of 30-50 nm GFs and (b) few-layer GF, (c, d) STEM image of the GFs interconnected by CNTs, with (d) showing CNTs bridging the GFs, (e, f) high-resolution STEM images taken from a graphene monolayer, showing the honeycomb structure, and $(\mathrm{g}, \mathrm{h})$ STEM images of double- or few-layer GFs. Individual metal atoms are observed as bright spots on the carbon support. 
electron, $>1 \mathrm{eV}$ in-plane kinetic energy can be transferred to a heavy nucleus such as that of $\mathrm{Co},{ }^{61}$ which is enough to activate adatom diffusion in few-layer graphene encapsulation. The fact that the metal atoms remained completely stable during our STEM experiments serves as a strong indication of their covalent nature. STEM images taken from the CNTs in the $\mathrm{N}-\mathrm{Co}-\mathrm{Mo}-\mathrm{GF} / \mathrm{CNT}$ material are shown in Figure S3. No metallic dopants were observed in the sidewall of CNTs, hinting that the CNTs are mainly a conductive network bridging the GFs for efficient electron transport, rather than providing additional active $\mathrm{M}-\mathrm{C}$ sites for electrocatalysis. Figure S4 shows single-, double-, and few-layer graphene nanoflakes in the synthesized material. In some parts of the sample, Co and Mo nanoparticles were also detected. The frequency at which the particles were observed was nevertheless much lower than that of the individual metallic atoms, as is also visible in Figure S5.

2.2.2. Raman Spectroscopy. Raman spectroscopy is a powerful method that allows the detection of graphitization in carbon nanomaterials. Generally, the Raman spectra of $\mathrm{sp}^{2}$ hybridized carbon exhibit major spectral components emerging from defects (D-band at $1300-1360 \mathrm{~cm}^{-1}$ ) and in-plane Gband vibrations at $1570-1600 \mathrm{~cm}^{-1} \cdot{ }^{62-64}$ Earlier studies have shown that the disorder-induced D-band is increased when the graphitic carbon lattice is doped with foreign atoms. ${ }^{64}$ Figure 3

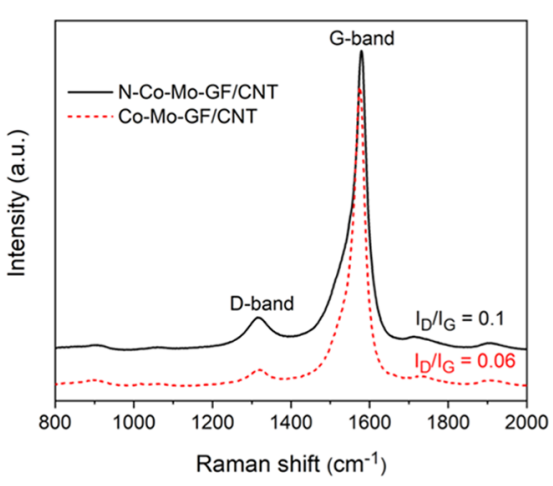

Figure 3. Raman spectra obtained from $\mathrm{N}-\mathrm{Co}-\mathrm{Mo}-\mathrm{GF} / \mathrm{CNT}$ (black line) and Co-Mo-GF/CNT (red dashed line) samples. The spectra show a low $I_{\mathrm{D}} / I_{\mathrm{G}}$ ratio for the one-step synthesized graphene/ CNT hybrids, reflecting the high level of graphitization of the samples. The data are normalized with respect to G-band intensities.

shows the Raman D- and G-bands of Co-Mo-GF/CNT with and without $\mathrm{N}$ heteroatom doping. The highly crystalline $\mathrm{sp}^{2}$ carbon structure of the Co-Mo-GF/CNT sample is reflected in its relatively low $I_{\mathrm{D}} / I_{\mathrm{G}}$ ratio of 0.06 . Nitrogen doping increased the $I_{\mathrm{D}} / I_{\mathrm{G}}$ ratio to 0.1 , which can be attributed to the substitution of $\mathrm{N}$ heteroatoms in the graphitic carbon. The observed ratio is significantly lower than that reported for other synthesized graphene-CNT hybrids in the literature. $^{25-27,31-33}$ This demonstrates that the synthesis method reported here allows the production of conductive heteroatomdoped graphene-CNT structures with higher quality than has previously been possible.

2.2.3. Pore-Size Analysis. Figure S6 shows the nitrogen adsorption-desorption isotherm of $\mathrm{N}-\mathrm{Co}-\mathrm{Mo}-\mathrm{GF} / \mathrm{CNT}$, which exhibits a typical $I V$-type isotherm curve with a distinct hysteretic loop associated with capillary condensation taking place in the mesopores. ${ }^{65,66}$ The shape of the hysteretic loop can be attributed to slit-shaped pores, which are observed for nonrigid aggregates of platelike particles. ${ }^{66}$ Figure S6 shows the cumulative pore volume and pore-size distributions of the $\mathrm{N}-$ Co-Mo-GF/CNT calculated using the Barrett-JoynerHalenda $(\mathrm{BJH})$ method, revealing an average pore width of $11.5 \mathrm{~nm}$. Moreover, a high specific surface area of $911 \mathrm{~m}^{2} \mathrm{~g}^{-1}$ was measured using the Brunauer-Emmett-Teller (BET) method.

2.3. Oxygen Reduction Activity and Discussion. To evaluate the activity of the $\mathrm{N}-\mathrm{Co}-\mathrm{Mo}-\mathrm{GF} / \mathrm{CNT}$ catalyst for ORR on various $\mathrm{Ni}, \mathrm{Au}$, and $\mathrm{GC}$ substrates, rotating disc electrode $(\mathrm{RDE})$ voltammetry measurements were carried out at different rotation rates in $0.1 \mathrm{M} \mathrm{KOH}$ (see details of the electrochemical procedures in the Supporting Information). Figure $4 \mathrm{a}$ demonstrates the ORR linear sweep voltammetry
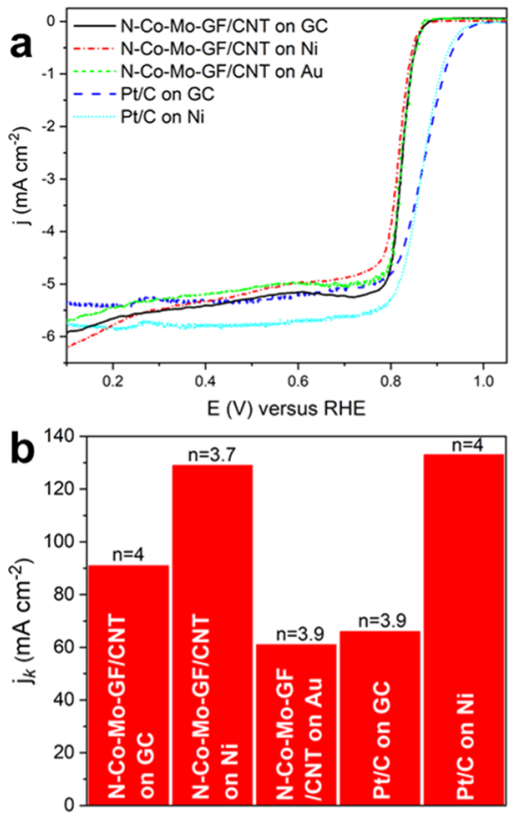

Figure 4. (a) ORR polarization curves in an $\mathrm{O}_{2}$-saturated $0.1 \mathrm{M} \mathrm{KOH}$ solution at $1600 \mathrm{rpm}$ and (b) ORR kinetic currents and number of transferred electrons obtained at $0.7 \mathrm{~V}$ vs RHE for $\mathrm{N}-\mathrm{Co}-\mathrm{Mo}-\mathrm{GF} /$ $\mathrm{CNT}$ on GC, Ni, and Au substrates, as well as for Pt/C on GC and $\mathrm{Ni}$ substrates.

(LSV) comparison of $\mathrm{N}-\mathrm{Co}-\mathrm{Mo}-\mathrm{GF} / \mathrm{CNT}$ and conventional $\mathrm{Pt} / \mathrm{C} 20 \mathrm{wt} \%$ on different substrates at a rotation of $1600 \mathrm{rpm}$. The corresponding ORR Tafel plots are depicted in Figure S7. The prepared catalyst exhibited a remarkable ORR catalytic activity on all of the substrates with a half-potential of $\sim 0.83 \mathrm{~V}$, and an onset potential of $\sim 0.9 \mathrm{~V}$ relative to the reversible hydrogen electrode (RHE). The ORR Tafel slopes for the N-Co-Mo-GF/CNT catalyst were 27, 37, and 44 $\mathrm{mV} \mathrm{dec}^{-1}$ on $\mathrm{Ni}, \mathrm{GC}$, and $\mathrm{Au}$ substrates, while, for $\mathrm{Pt} / \mathrm{C}$, they were $54 \mathrm{mV} \mathrm{dec}^{-1}$ on both GC and Ni substrates (Figure S7).

The kinetic current and the number of electrons involved per $\mathrm{O}_{2}$ in the ORR on $\mathrm{N}-\mathrm{Co}-\mathrm{Mo}-\mathrm{GF} / \mathrm{CNT}$ were calculated based on the Koutecky-Levich (K-L) equation, as explained in the Supporting Information. The ORR LSV polarization curves at various rotation rates $(400,700,900,1200,1600$, 2000, and $2500 \mathrm{rpm}$ ) for $\mathrm{N}-\mathrm{Co}-\mathrm{Mo}-\mathrm{GF} / \mathrm{CNT}$ on GC, Ni, and $\mathrm{Au}$ substrates and for $\mathrm{Pt} / \mathrm{C}$ on $\mathrm{GC}$ and $\mathrm{Ni}$ substrates, together with the corresponding linear $\mathrm{K}-\mathrm{L}$ plots through the inverse current density $\left(j^{-1}\right)$ as a function of the inverse of the square root of the rotation speed $\left(\omega^{-1 / 2}\right)$ at $0.7 \mathrm{~V}$, are shown in 
Figure S8. The kinetic current density $\left(j_{\mathrm{k}}\right)$, measured from the $y$-intercept of linear $\mathrm{K}-\mathrm{L}$ plots at a potential of $0.7 \mathrm{~V}$ vs RHE, is depicted in Figure $4 \mathrm{~b}$. For the $\mathrm{N}-\mathrm{Co}-\mathrm{Mo}-\mathrm{GF} / \mathrm{CNT}$ on various substrates, $j_{\mathrm{k}}$ increased from $91 \mathrm{~mA} \mathrm{~cm}^{-2}$ on GC to 129 $\mathrm{mA} \mathrm{cm} \mathrm{cm}^{-2}$ on $\mathrm{Ni}$, but decreased to $61 \mathrm{~mA} \mathrm{~cm}^{-2}$ on the $\mathrm{Au}$ substrate. Similarly, for Pt/C, the improvement in $j_{\mathrm{k}}$ on GC vs the Ni substrate was significant, so that $j_{\mathrm{k}}$ increased from 66 to $133 \mathrm{~mA} \mathrm{~cm}{ }^{-2}$. These results show that the $\mathrm{Ni}$ substrate can considerably improve the ORR kinetic current for both $\mathrm{Pt} / \mathrm{C}$ and $\mathrm{N}-\mathrm{Co}-\mathrm{Mo}-\mathrm{GF} / \mathrm{CNT}$ catalysts, rendering $\mathrm{Ni}$ a promising substrate for alkaline ORR. The corresponding number of transferred electrons on all tested substrates was close to 4 (Figure 4b), indicating that the ORR was dominated by a fourelectron process.

Retention of the ORR current was approximately $97 \%$ under $0.70 \mathrm{~V}$ for $21 \mathrm{~h}$ using the $\mathrm{N}-\mathrm{Co}-\mathrm{Mo}-\mathrm{GF} / \mathrm{CNT}$ electrocatalyst, showing higher stability than Pt/C (Figure S9). The $\mathrm{N}-\mathrm{Co}-\mathrm{Mo}-\mathrm{GF} / \mathrm{CNT}$ electrocatalyst also exhibited an improved ORR catalytic activity and stability in comparison to the previously reported multi-heteroatom-doped porous carbon catalyst. ${ }^{67}$ The activity of this catalyst for ORR is comparable to that of the best heteroatom-doped carbon nanomaterials, ${ }^{2}$ nonprecious $\mathrm{M}-\mathrm{N}-\mathrm{C},{ }^{3,4,68-71}$ and single(and few-) atom ${ }^{72}$ ORR electrocatalysts reported so far in terms of the ORR half-wave potential, kinetic current density, and stability.

2.4. Oxygen Evolution Activity and Discussion. The electrocatalytic activity of $\mathrm{N}-\mathrm{Co}-\mathrm{Mo}-\mathrm{GF} / \mathrm{CNT}$ for OER was also investigated by RDE measurements in $0.1 \mathrm{M} \mathrm{KOH}$. The OER polarization curves of the prepared catalyst on GC, $\mathrm{Ni}$, and $\mathrm{Au}$ substrates are compared with a well-established water oxidation catalyst, $\mathrm{RuO}_{2}$, on $\mathrm{GC}$ and $\mathrm{Ni}$ substrates in Figure 5a. On the GC substrate, $\mathrm{RuO}_{2}$ exhibited a slightly higher activity at low current densities $\left(<20 \mathrm{~mA} \mathrm{~cm}^{-2}\right)$ than $\mathrm{N}-\mathrm{Co}-$ Mo-GF/CNT. However, at high current densities $(\gg 20 \mathrm{~mA}$ $\mathrm{cm}^{-2}$ ), the synthesized catalyst suppressed $\mathrm{RuO}_{2}$ tested in this work so that it required a potential of $1.68 \mathrm{~V}$, rather than 1.72 $\mathrm{V}$ for $\mathrm{RuO}_{2}$, to reach a current of $50 \mathrm{~mA} \mathrm{~cm}{ }^{-2}$. In contrast to manganese- and cobalt-based oxides ${ }^{38-41,44}$ and $\mathrm{NiCeO}_{x}{ }^{43}$ which demonstrate drastic improvements in activity for OER when the surface or substrate is enriched with $\mathrm{Au}$, we did not observe a significant enhancement of activity with an Au substrate. Nevertheless, the OER activity of the N-Co-MoGF/CNT catalyst was remarkably enhanced when it was coated on a $\mathrm{Ni}$ substrate. The onset overpotential and the required overpotential to reach $10 \mathrm{~mA} \mathrm{~cm} \mathrm{~cm}^{-2}\left(\eta_{\mathrm{OER}, 10}\right)$ decreased by $\sim 50$ and $\sim 77 \mathrm{mV}$, respectively, on $\mathrm{Ni}$ in comparison to the GC substrate. For $\mathrm{RuO}_{2}$, the onset overpotential over $\mathrm{Ni}$ was similar to that over GC, but the ORR current improved and the $\eta_{\mathrm{OER}, 10}$ was ca. $26 \mathrm{mV}$ lower. Nonetheless, for the N-Co-Mo-GF/CNT catalyst, which has a high-surface-area mesoporous structure, the electrolyte can more readily permeate the underlying layers and the $\mathrm{Ni}$ / catalyst interface, where a synergistic effect occurs, forming new active sites with a higher reactivity and a lower onset overpotential. Figure S10 illustrates the synergistic effect between the $\mathrm{Ni}$ substrate and the $\mathrm{N}-\mathrm{Co}-\mathrm{Mo}-\mathrm{GF} / \mathrm{CNT}$ electrocatalyst for enhancing activity for OER. The OER Tafel plots of the prepared catalyst and $\mathrm{RuO}_{2}$ are shown in Figure $5 b$. The Tafel slope values for the $\mathrm{N}-\mathrm{Co}-\mathrm{Mo}-\mathrm{GF} / \mathrm{CNT}$ catalyst on $\mathrm{Ni}, \mathrm{Au}$, and $\mathrm{GC}$ substrates follow a trend of $\mathrm{Ni}<$ $\mathrm{GC}<\mathrm{Au}$, where a lower slope indicates a more active electrode. $\mathrm{RuO}_{2}$ also had a lower Tafel slope on $\mathrm{Ni}$ than on
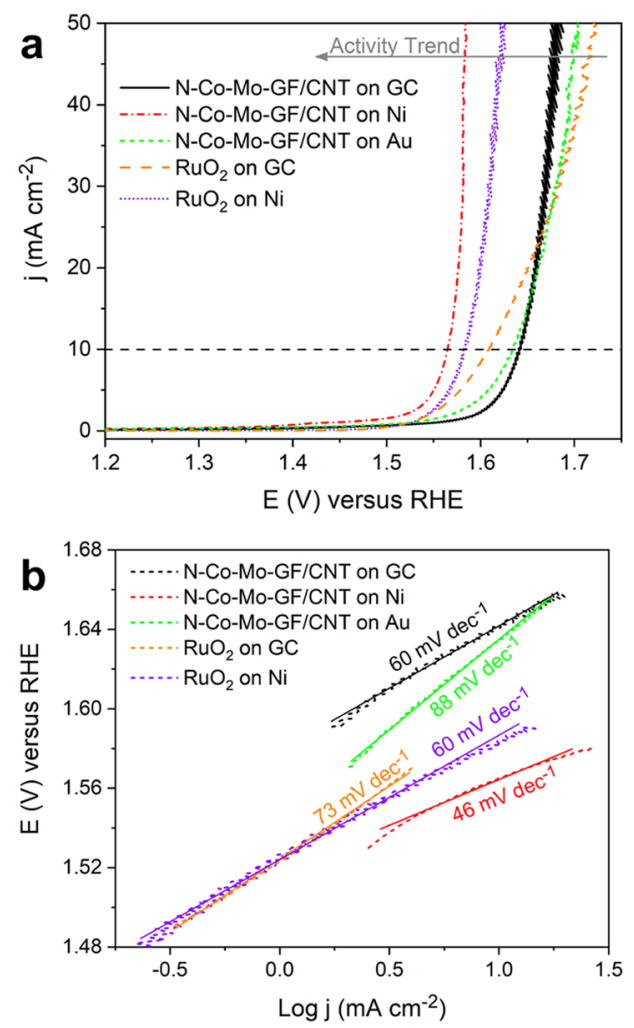

Figure 5. (a) OER polarization curves and (b) corresponding OER Tafel plots of the N-Co-Mo-GF/CNT catalyst on GC, Ni, and Au compared to $\mathrm{Pt} / \mathrm{C}$ on $\mathrm{GC}$ and $\mathrm{Ni}$ substrates in $0.1 \mathrm{M} \mathrm{KOH}$.

GC. Since the Tafel slope is related to the reaction mechanism, the difference perhaps arises from a change in the ratedetermining step of the OER.

The $\mathrm{N}-\mathrm{Co}-\mathrm{Mo}-\mathrm{GF} / \mathrm{CNT}$ catalyst on $\mathrm{Ni}$ required overpotentials of just 330 and $350 \mathrm{mV}$ to reach 10 and $50 \mathrm{~mA} \mathrm{~cm}$ (denoted $\eta_{\mathrm{OER}, 10}$ and $\left.\eta_{\mathrm{OER}, 50}\right)$, respectively. The catalyst's performance upon a $24 \mathrm{~h}$ continuous operation at $20 \mathrm{~mA} \mathrm{~cm} \mathrm{~m}^{-2}$ was also highly stable (Figure S11). The OER electrocatalytic performance of $\mathrm{N}-\mathrm{Co}-\mathrm{Mo}-\mathrm{GF} / \mathrm{CNT}$ on $\mathrm{Ni}$ was close to that reported previously for highly active OER electrocatalysts, ${ }^{2,73-78}$ especially at high currents.

Substrate effects enhancing the OER activity of $\mathrm{RuO}_{2}$ have recently been reported. ${ }^{79}$ Here, we demonstrated that for a mesoporous electrolyte-permeable catalyst, such as $\mathrm{N}-\mathrm{Co}-$ $\mathrm{Mo}-\mathrm{GF} / \mathrm{CNT}$, the role of the substrate could be more significant. We believe that this represents a route to further developing the activity of mesoporous carbon-based catalysts through the addition of suitable active metals to the substrate, or to the surface of the catalyst, where new active sites are formed at the metal/catalyst interface.

Hence, the high-surface-area mesoporous N-Co-Mo-GF/ CNT hybrid material represents a stable ORR/OER electrocatalyst with a high activity that can be further improved using a Ni substrate. This catalyst exhibited an advanced electrocatalytic performance in terms of both ORR and OER activities compared to the best bifunctional ORR/OER catalysts reported in the literature. ${ }^{2,80-85}$

2.5. Active Sites for Oxygen Evolution and Reduction Reactions. 2.5.1. Active Sites Over the Glassy Carbon Substrate. The $\mathrm{C}-\mathrm{C}$ sites in pristine graphene and CNTs are almost catalytically inactive. Carbon nanomaterials doped by heteroatoms, however, form new active sites that can activate 
them for ORR ${ }^{20-22}$ and OER. ${ }^{23,24}$ In the case of the $\mathrm{N}-\mathrm{Co}-$ Mo-GF/CNT catalyst as an $\mathrm{M}-\mathrm{N}-\mathrm{C}$ catalyst, the $\mathrm{N}-\mathrm{C}$ and/ or the $\mathrm{M}$ (Co, and Mo) $-\mathrm{C}$ sites act as the active sites for ORR and OER. To find out whether the $\mathrm{N}-\mathrm{C}$ and/or $\mathrm{M}-\mathrm{C}$ sites are responsible for the observed activity, an electrocatalyst was synthesized without the temporary introduction of acetonitrile, thus lacking a nitrogen source (see Section 2.1 above). This material is denoted $\mathrm{Co}-\mathrm{Mo}-\mathrm{GF} / \mathrm{CNT}$.

The comparison of the ORR activity of the Co-Mo-GF/ $\mathrm{CNT}$ and $\mathrm{N}-\mathrm{Co}-\mathrm{Mo}-\mathrm{GF} / \mathrm{CNT}$ samples (Figures $6 \mathrm{a}$ and
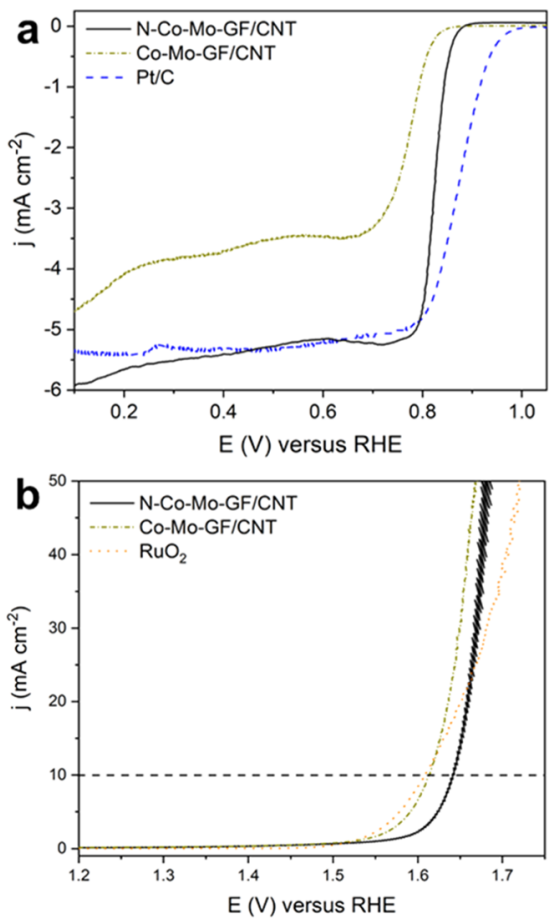

Figure 6. Effect of $\mathrm{N}$ heteroatoms on the ORR and OER activities of the $\mathrm{N}-\mathrm{Co}-\mathrm{Mo}-\mathrm{GF} / \mathrm{CNT}$ electrocatalyst. (a) ORR and (b) OER polarization curves of $\mathrm{Co}-\mathrm{Mo}-\mathrm{GF} / \mathrm{CNT}$ compared to that of N$\mathrm{Co}-\mathrm{Mo}-\mathrm{GF} / \mathrm{CNT}$. The polarization curves were obtained in a 0.1 $\mathrm{M} \mathrm{KOH}$ solution at a scan rate of $5 \mathrm{mV} \mathrm{s}^{-1}$ and a $1600 \mathrm{rpm}$ rotation speed. The electrocatalysts were deposited on a GC substrate.

S12) revealed that the material without $\mathrm{N}$ sites remained active for ORR, but that its activity was considerably lower than that in the presence of $\mathrm{N}$ heteroatoms. In comparison, doping with $\mathrm{N}$ sites resulted in an ORR half-wave potential increase of $\sim 50$ $\mathrm{mV}$ and a 7-fold enhancement in kinetic current density (from 13 to $91 \mathrm{~mA} \mathrm{~cm}{ }^{-2}$ at $\left.0.7 \mathrm{~V}\right)$. Meanwhile, the number of transferred electrons also increased from 3.2 to 4 (Figure S12). This change in ORR activity indicates that both the $\mathrm{N}-\mathrm{C}$ and $\mathrm{M}-\mathrm{C}$ sites are synergistically responsible for ORR activity.

The comparison of the OER activity of the Co-Mo-GF/ CNT and N-Co-Mo-GF/CNT samples is shown in Figure 6b. Doping with $\mathrm{N}$ sites increased the $\eta_{\mathrm{OER}, 10}$ and $\eta_{\mathrm{OER}, 50}$ by 27 and $13 \mathrm{mV}$, respectively, indicating that the sample without $\mathrm{N}$ has slightly higher OER activity than the $\mathrm{N}$-doped sample. The Tafel slope of the $\mathrm{N}$-doped sample is, however, slightly lower than that without N (Figure S13). We can, therefore, conclude that the main OER active sites in the $\mathrm{N}-\mathrm{Co}-\mathrm{Mo}-\mathrm{GF} / \mathrm{CNT}$ are likely to be the $\mathrm{M}-\mathrm{C}$ sites. The slight decrease in OER activity after doping with $\mathrm{N}$ heteroatoms can be attributed to the increase in the number of defect sites in the graphitic network, which is also corroborated by Raman spectroscopy (Figure 3). The stability of Co-Mo-GF/CNT for OER was also tested by a chronopotentiometry measurement at $20 \mathrm{~mA}$ $\mathrm{cm}^{-2}$, where a stable performance upon continuous operation for $12 \mathrm{~h}$ was observed (Figure S14).

2.5.2. Active Sites over the Ni Substrate. 2.5.2.1. X-ray Photoelectron Spectroscopy (XPS): Investigating the Possibility of Ni Diffusion into the Catalyst Film, and Changes in Catalyst Surface Composition during Electrocatalysis. XPS was used to study the chemical composition of the $\mathrm{N}-\mathrm{Co}-$ Mo-GF/CNT sample. Figure 7 shows the cobalt 2p, molybdenum $3 \mathrm{~d}$, and nitrogen $1 \mathrm{~s}$ regions of the sample both before and after electrochemical ORR and OER measurements. The related carbon 1s, oxygen 1s, and survey spectra, as well as atomic concentrations, are provided in the Supporting Information (Figure S15 and Table S1).

Figure $7 \mathrm{a}$ displays the Co $2 \mathrm{p}$ spectra of the $\mathrm{N}-\mathrm{Co}-\mathrm{Mo}-$ $\mathrm{GF} / \mathrm{CNT}$ sample. The Co $2 \mathrm{p}_{3 / 2}$ peak has been deconvoluted assuming the presence of two chemical states: $\mathrm{Co}(0)$ and $\mathrm{Co}(\mathrm{II}) .{ }^{86}$ In the pristine material, mainly $\mathrm{Co}(0)$ is found at a $2 \mathrm{p}_{3 / 2}$ binding energy of $778.1 \mathrm{eV}$, but a ca. $25 \%$ contribution of $\mathrm{Co}(\mathrm{II})$ is also required to explain the spectra. The binding energies and spectral shape correspond to $\mathrm{Co}(0)$. After OER, a typical Co $2 \mathrm{p}$ spectrum of $\mathrm{Co}$ (II) is observed, with a $2 \mathrm{p}_{3 / 2}$ peak at roughly $780.24 \mathrm{eV},{ }^{86}$ and a small contribution from $\mathrm{Co}(0)$ is still observed at $\sim 778 \mathrm{eV}$.

The Mo $3 \mathrm{~d}$ spectra are shown in Figure $7 \mathrm{~b}$. The spectra have been deconvoluted, assuming the presence of $\mathrm{Mo}(0)$ and $\mathrm{Mo}(\mathrm{VI}){ }^{87}$ In the pristine material, the spectrum shows a clear $3 \mathrm{~d}_{5 / 2}$ peak at $228.2 \mathrm{eV}$ corresponding to $\mathrm{Mo}(0)$ and another $3 \mathrm{~d}_{5 / 2}$ peak at roughly $232.3 \mathrm{eV}$ corresponding to $\mathrm{Mo}(\mathrm{VI}){ }^{87}$ The $3 \mathrm{~d}_{3 / 2}$ peak of $\mathrm{Mo}(0)$ at roughly $231.3 \mathrm{eV}$ overlaps with the $\mathrm{Mo}(\mathrm{VI}) 3 \mathrm{~d}_{5 / 2}$ peak. The $3 \mathrm{~d}_{3 / 2}$ peak of $\mathrm{Mo}(\mathrm{VI})$ is found at a binding energy of $235.5 \mathrm{eV}$. After ORR/OER, the Mo $3 \mathrm{~d}$
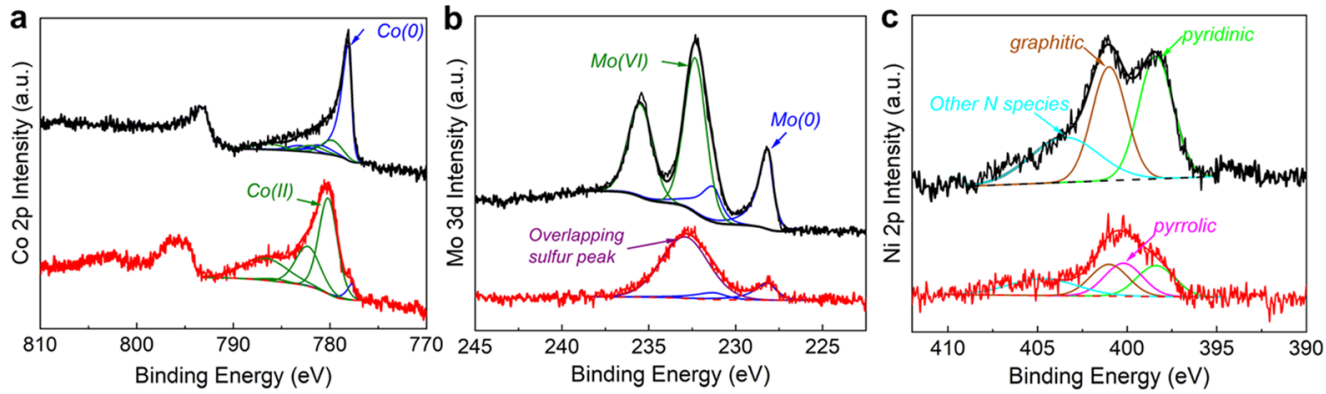

Figure 7. X-ray photoelectron spectra of the $\mathrm{N}-\mathrm{Co}-\mathrm{Mo}-\mathrm{GF} / \mathrm{CNT}$ catalyst before (black lines) and after (red lines) the ORR and OER measurements on the Ni substrate: (a) Co 2 p region, (b) Mo $3 \mathrm{~d}$ region, and (c) N 1s region including the deconvolution. 

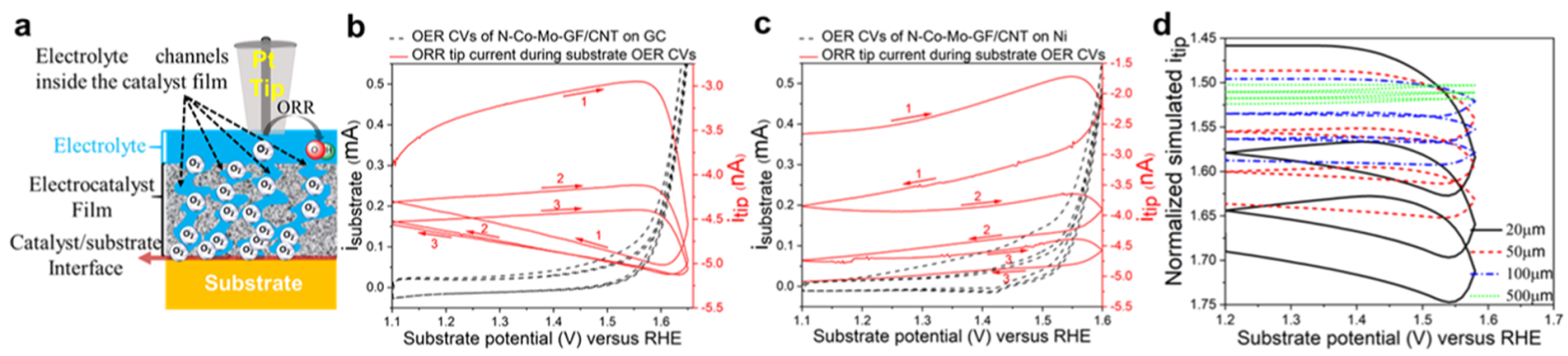

Figure 8. (a) Schematic representation of the Pt SECM tip for approaching the electrocatalyst surface to observe the feedback from the electrocatalyst and substrate, as well as $\mathrm{O}_{2}$ diffusion from the substrate/catalyst interface to the tip. (b, c) Results of substrate generation-tip collection experiments, where the substrate potential was scanned to the OER region at a scan rate of $5 \mathrm{mV} \mathrm{s}{ }^{-1}$, while the tip potential was kept at a constant value of $0.3 \mathrm{~V}$ to drive ORR. The tip was placed close to the surface of $\mathrm{N}-\mathrm{Co}-\mathrm{Mo}-\mathrm{GF} / \mathrm{CNT}$ on (b) GC and (c) Ni substrates. (d) Simulated transient tip ORR currents obtained for the experimental OER CVs in (c) for the several oxygen diffusion distances, showing that a similar ORR tip current response to that experimentally measured in (c) is reproduced if the OER takes place significantly further from the catalyst top surface, at approximately $5 \mu \mathrm{m}$ from the tip. The tip current in (d) is normalized by the ORR current in the bulk.

spectrum is dominated by an overlapping sulfur $2 \mathrm{~s}$ peak at roughly $232.9 \mathrm{eV}$, which is attributed to sulfate impurities from the electrolyte. Some $\mathrm{Mo}(0)$ is still observed, but its contribution has been clearly reduced (see Table $S 1$ in the Supporting Information). Also, the lack of a $3 \mathrm{~d}_{3 / 2}$ peak at $235.54 \mathrm{eV}$ related to $\mathrm{Mo}(\mathrm{VI})$ indicates that the amount of oxidized molybdenum has significantly decreased.

The oxidation of Co and Mo after OER measurements can be attributed to the Co and Mo nanoparticles that were initially encapsulated in carbon layers but oxidized during the OER. During the OER, the graphene layers that protect the metal nanoparticles can be stripped off (Figure S16) due to the presence of highly reactive pentagonal rings and significant strain on the $\mathrm{C}-\mathrm{C}$ bonds. This causes permeation of the electrolyte into the metal core and subsequent oxidation. ${ }^{77}$ The decrease in the amount of Mo after the electrochemical measurements can be attributed to the anodic dissolution of molybdenum in the alkaline solution. ${ }^{88}$

Figure $7 \mathrm{c}$ shows high-resolution $\mathrm{N} 1 \mathrm{~s}$ spectra of the $\mathrm{N}-\mathrm{Co}-$ Mo-GF/CNT sample before and after the electrochemical measurements. The spectra have been deconvoluted assuming a generally used model with the following $\mathrm{N}$-functional groups: pyridinic-N (ca. $398.3 \mathrm{eV}$ ), pyrrolic-N (ca. $400.1 \mathrm{eV}$ ), graphitic-N (ca. $400.9 \mathrm{eV}$ ), and other $\mathrm{N}$ species (ca. 403$405 \mathrm{eV}) .{ }^{89,90}$ The peak in binding energies between 403 and $405 \mathrm{eV}$ can be attributed to various oxidized nitrogen configurations, clustered $\mathrm{N}$ substitutions, hydrogenation of the nitrogen dopants, and $\mathrm{N}_{2}$ molecules trapped inside carbon nanotubes or between graphene layers. ${ }^{89}$ The relative concentrations of the different nitrogen species in the pristine sample were $38 \%$ pyridinic-N, $35 \%$ graphitic-N, and $27 \%$ other $\mathrm{N}$ species. After OER, the pyrrolic-N component was also required for a satisfactory fit, yielding relative concentrations of $25 \%$ pyridinic-N, $26 \%$ pyrrolic-N, $25 \%$ graphitic-N, and $24 \%$ other $\mathrm{N}$ species. The XPS analysis of the $\mathrm{N}-\mathrm{Co}-\mathrm{Mo}-\mathrm{GF} /$ $\mathrm{CNT}$ sample revealed the presence of 1 atom $\% \mathrm{~N}$ before and after ORR/OER measurements (Table S1).

According to earlier experimental work with graphene nanoribbon networks doped with nitrogen, the electrondonating graphitic- $\mathrm{N}$ moieties serve as active sites for ORR, while the electron-withdrawing pyridinic- $\mathrm{N}$ sites are responsible for OER. ${ }^{1}$ Here, however, we could not verify that the $\mathrm{N}$ moieties served as the active sites for OER, but, instead, we observed that single metal atoms in the graphene flakes were the main sites responsible for OER.
To detect possible Ni diffusion from the substrate into the $\mathrm{N}-\mathrm{Co}-\mathrm{Mo}-\mathrm{GF} / \mathrm{CNT}$ film during electrochemical measurements, the catalyst material over the $\mathrm{Ni}$ substrate was transferred onto an $\mathrm{Au}$ substrate after the ORR/OER measurements. This prevented substrate $\mathrm{Ni}$ detection in the XPS measurements. In these measurements, $\mathrm{Ni}$ was not detected, meaning that $\mathrm{Ni}$ did not diffuse into the catalyst during the electrochemical measurements. This is in clear contrast to what has been observed for $\mathrm{NiCeO}_{x}$ deposited onto an $\mathrm{Au}$ electrode, in which XPS depth profiles demonstrated that $\mathrm{Au}$ from the substrate could diffuse into the catalyst film. ${ }^{43}$

2.5.2.2. Scanning Electrochemical Microscopy (SECM) Analysis: Unraveling Where the OER Reaction Takes Place on the Ni Substrate. The OER takes place on the catalyst surface and/or in the underlying layers where new sites are formed at the substrate/catalyst interface. To study where the OER reaction actually takes place, scanning electrochemical microscopy (SECM) was used. SECM is a scanning probe technique capable of imaging local reactivity at a high spatial resolution. Here, using SECM, we established that the enhanced OER activity of $\mathrm{N}-\mathrm{Co}-\mathrm{Mo}-\mathrm{GF} / \mathrm{CNT}$ over the $\mathrm{Ni}$ (rather than the GC) substrate was due to newly formed interfacial sites, thus yielding a synergistic effect.

Figure S17 shows the theoretical approach curves of the SCEM tip for the positive (enhancement in the tip current) and negative (reduction in the tip current) feedbacks, as well as the overlay of the experimental approach curves for the tip on $\mathrm{Ni}$ and on the $\mathrm{N}-\mathrm{Co}-\mathrm{Mo}-\mathrm{GF} / \mathrm{CNT}$ mesoporous film deposited on $\mathrm{Ni}$. A similar response was also observed on the GC substrate (data not shown here). A negative feedback to the tip ORR current was observed over both GC and $\mathrm{Ni}$ when approaching the surface (Figure S17) because the substrate can block the flux of the oxygen to the Pt tip. In contrast, for the $\mathrm{N}-\mathrm{Co}-\mathrm{Mo}-\mathrm{GF} / \mathrm{CNT}$ mesoporous film, a positive feedback on the Pt tip was observed, as illustrated in Figure S17. This indicates that some oxygen was trapped within the catalyst layer due to hydrophobicity or the porous surface structure of the GFs and CNTs. A similar observation has been reported when approaching a porous poly(vinylidene fluoride) membrane. ${ }^{91}$ As the tip depletes oxygen from the solution, oxygen from the porous film partitions into the solution, resulting in similar behavior to that observed when approaching a water-air interface. ${ }^{92-94}$ The simulations described in the Supporting Information and Figures S17 and S18 were conducted to reproduce the positive feedback for 
the tip approach curve over a porous catalyst, which traps oxygen molecules within the porous layer. Mass transport in porous electrodes has been studied previously ${ }^{95}$ by SECM, but not with gaseous species partitioning into the porous electrode. The simulated approach curve reproduced well the experimentally observed positive feedback to the ORR tip current that was obtained on the $\mathrm{N}-\mathrm{Co}-\mathrm{Mo}-\mathrm{GF} / \mathrm{CNT}$ electrocatalyst surface as shown in Figure S17. The oxygen from the film could be depleted by applying a sufficiently low potential ( $\sim 0-0.3 \mathrm{~V}$ vs RHE) to the substrate for reducing oxygen. When this was done with the Pt tip (kept at $0.3 \mathrm{~V}$ vs RHE) near the substrate, the ORR tip current approached zero. Interestingly, when the substrate potential was removed, after a sufficient time, a positive feedback was again observed when approaching the mesoporous film. This indicates that the dissolved oxygen from the solution can partition into the porous electrode, thus restoring the initial situation.

In the substrate generation-tip collection (SG-TC) mode of SECM, as schematically shown in Figure 8a, oxygen that evolves on the substrate during the OER is subsequently reduced and detected on the probe tip placed close to the substrate surface. ${ }^{96}$ When OER cyclic voltammetry $(\mathrm{CV})$ is carried out on the substrate, the ORR current response on the SECM tip will vary depending on the distance between the tip and the sites at which OER takes place on the substrate. ${ }^{96}$ Here, depending on how the SECM tip current responds to the formation of $\mathrm{O}_{2}$ on the substrate, we can interpret whether the OER takes place within the catalyst layer or at the catalyst/ substrate interface. This approach can hence confirm whether the enhanced activity of $\mathrm{N}-\mathrm{Co}-\mathrm{Mo}-\mathrm{GF} / \mathrm{CNT}$ over the $\mathrm{Ni}$ (rather than the GC) substrate is indeed due to newly formed interfacial sites with a synergistic effect.

The SG-TC SECM experiments were carried out with the $\mathrm{N}-\mathrm{Co}-\mathrm{Mo}-\mathrm{GF} / \mathrm{CNT}$ catalyst deposited on GC (Figure 8b) and $\mathrm{Ni}$ (Figure 8c) substrates. The substrate potential was scanned to the OER region, while the tip potential was kept at a constant value of $0.3 \mathrm{~V}$ to drive the ORR sufficiently. The experimental results in Figure $8 \mathrm{c}$ show that it took much longer for oxygen to reach the tip when $\mathrm{Ni}$ was used as the substrate, resulting in a stepwise increase in the tip current. When GC was used as the substrate, the response was more immediate but also decayed much faster. This indicates that when $\mathrm{Ni}$ was used as the substrate, the evolved oxygen remained in the catalyst layer, while, on GC, the oxygen was released faster. To simulate this effect qualitatively, the oxygen diffusion distance to the tip was varied between 20 and $500 \mu \mathrm{m}$ by increasing the thickness of the porous layer, as shown in Figure $8 \mathrm{~d}$. Simulations showed that when the diffusion distance was small, the tip response was fast, and the decay in the current was also more rapid. When the distance increased, however, the time for oxygen to reach the tip was greater, leading to a similar response to that observed experimentally on the $\mathrm{Ni}$ substrate (Figure 8c). This indicates that on GC, oxygen evolution takes place close to the catalyst surface and/or the oxygen is released rapidly from the catalyst layer. Meanwhile, on the Ni substrate, OER takes place deeper in the catalyst layer (see Scheme S1). These results indicate that OER, in fact, takes place close to the electrocatalyst/Ni interface, where new active sites can be formed with a higher OER electrocatalytic activity than that of sites on the catalyst surface. These results are in good agreement with an earlier report by Snook et al. ${ }^{96}$ They demonstrated that by increasing the distance between the tip and the substrate, the ORR current on the tip does not immediately decrease when the OER current on the substrate is reduced during the backward scan of OER CV, due to the time required for the oxygen generated at the substrate to diffuse to the probe tip. As a result, when the $\mathrm{O}_{2}$ diffusion length from the substrate is increased, the ORR on the tip also takes place later than the OER onset potential. ${ }^{96}$ This also explains why the ORR tip current in Figure $8 \mathrm{~b}$ increases at almost the same time at which the substrate starts to produce $\mathrm{O}_{2}$ (at OER onset potential), while, in Figure $8 \mathrm{c}$, the enhancement in the tip current takes place later than $\mathrm{O}_{2}$ production on the substrate. These SG-TC SECM experiments thus provide a novel technique to observe where the electrocatalytic reaction takes place in porous multilayer electrocatalysts.

\section{CONCLUSIONS}

In summary, a high-surface-area mesoporous hybrid of graphene nanoflakes and CNTs doped with single atoms of $\mathrm{N}, \mathrm{Co}$, and Mo has been synthesized using a fast and scalable, low-cost one-step chemical vapor deposition process. The material shows high activity and stability for catalyzing ORR and OER in alkaline media. In the prepared catalyst, we demonstrate that $\mathrm{N}-\mathrm{C}$ sites do not serve as the main active sites for OER activity, although they do have a synergistic effect with $\mathrm{M}-\mathrm{C}$ sites, thus enhancing activity for ORR. We have further demonstrated how the use of $\mathrm{Ni}, \mathrm{Au}$, and $\mathrm{GC}$ substrates affects the electrocatalytic activity of the synthesized catalyst for ORR and OER. The use of a Ni substrate, in comparison to GC and $\mathrm{Au}$, increases the ORR kinetic current and significantly improves the OER activity of the mesoporous catalyst. Based on XPS analysis, no Ni diffusion from the substrate to the porous catalyst was detected during the electrochemical measurements. Instead, enhanced electrocatalytic activity is attributed to the catalyst/Ni interfacial sites that are accessible through the pores of the electrocatalyst film. By applying the developed SECM analysis method, we further confirm that instead of the catalyst surface, a significant amount of the evolved $\mathrm{O}_{2}$ at the low overpotentials during OER originated from the underlying catalyst/Ni interface. We have thus established a new catalyst for alkaline OER and ORR with tunable reactivity depending on the choice of the underlying substrate, which opens new avenues for the growth of heteroatom-doped graphene-CNT hybrids for various applications.

\section{ASSOCIATED CONTENT}

\section{(s) Supporting Information}

The Supporting Information is available free of charge at https://pubs.acs.org/doi/10.1021/acscatal.0c00352.

STEM and TEM images; $\mathrm{N}_{2}$ adsorption/desorption isotherms; additional electrochemical ORR and OER measurements; additional details on electrochemical procedures, physical, and chemical characterizations; XPS; SECM analysis; and related references (PDF)

\section{AUTHOR INFORMATION}

\section{Corresponding Author}

Mohammad Tavakkoli - Department of Applied Physics, Aalto University School of Science, FI-00076 Aalto, Finland; 기이.org/0000-0003-4859-1922;

Phone: +358504140950; Email: mohammad.tavakkoli@ aalto.fi 


\section{Authors}

Emmanuel Flahaut - CIRIMAT, Universite de Toulouse, CNRS, INPT, UPS, UMR CNRS-UPS-INP No 5085, Universite Toulouse 3 Paul Sabatier, 31062 Toulouse, France

Pekka Peljo - Research Group of Physical Electrochemistry and Electrochemical Physics, Department of Chemistry and Material Sciences, Aalto University School of Chemical Engineering, FI00076 Aalto, Finland; (1) orcid.org/0000-0002-1229-2261

Jani Sainio - Department of Applied Physics, Aalto University School of Science, FI-00076 Aalto, Finland

Fatemeh Davodi - Department of Chemistry and Material Sciences, Aalto University School of Chemical Engineering, FI00076 Aalto, Finland

Egor V. Lobiak - Nikolaev Institute of Inorganic Chemistry, SB RAS, 630090 Novosibirsk, Russia; ㅇo이.org/0000-00015085-5531

Kimmo Mustonen - Faculty of Physics, University of Vienna, 1090 Vienna, Austria; 이이이.org/0000-0002-0953-7299

Esko I. Kauppinen - Department of Applied Physics, Aalto University School of Science, FI-00076 Aalto, Finland; (1) orcid.org/0000-0003-1727-8810

Complete contact information is available at: https://pubs.acs.org/10.1021/acscatal.0c00352

\section{Notes}

The authors declare no competing financial interest.

\section{ACKNOWLEDGMENTS}

This work has been supported by the Academy of Finland (ANCED project) and the Magnus Ehrnooth Foundation. The authors also thank Prof. Kari Laasonen for fruitful discussions and Dr. Hua Jiang for taking the TEM images.

\section{REFERENCES}

(1) Yang, H. B.; Miao, J.; Hung, S.-F.; Chen, J.; Tao, H. B.; Wang, X.; Zhang, L.; Chen, R.; Gao, J.; Chen, H. M.; Dai, L.; Liu, B. Identification of catalytic sites for oxygen reduction and oxygen evolution in N-doped graphene materials: Development of highly efficient metal-free bifunctional electrocatalyst. Sci. Adv. 2016, 2, No. e1501122.

(2) Paul, R.; Du, F.; Dai, L.; Ding, Y.; Wang, Z. L.; Wei, F.; Roy, A. 3D Heteroatom-Doped Carbon Nanomaterials as Multifunctional Metal-Free Catalysts for Integrated Energy Devices. Adv. Mater. 2019, 31, No. 1805598.

(3) Lee, S. H.; Kim, J.; Chung, D. Y.; Yoo, J. M.; Lee, H. S.; Kim, M. J.; Mun, B. S.; Kwon, S. G.; Sung, Y.-E.; Hyeon, T. Design Principle of Fe-N-C Electrocatalysts: How to Optimize Multimodal Porous Structures? J. Am. Chem. Soc. 2019, 141, 2035-2045.

(4) Yan, X.-H.; Xu, B.-Q. Mesoporous carbon material co-doped with nitrogen and iron $(\mathrm{Fe}-\mathrm{N}-\mathrm{C})$ : high-performance cathode catalyst for oxygen reduction reaction in alkaline electrolyte. $J$. Mater. Chem. A 2014, 2, 8617-8622.

(5) Wu, G.; More, K. L.; Johnston, C. M.; Zelenay, P. HighPerformance Electrocatalysts for Oxygen Reduction Derived from Polyaniline, Iron, and Cobalt. Science 2011, 332, 443-447.

(6) Parvez, K.; Yang, S.; Hernandez, Y.; Winter, A.; Turchanin, A.; Feng, X.; Müllen, K. Nitrogen-Doped Graphene and Its Iron-Based Composite As Efficient Electrocatalysts for Oxygen Reduction Reaction. ACS Nano 2012, 6, 9541-9550.

(7) Davodi, F.; Mühlhausen, E.; Tavakkoli, M.; Sainio, J.; Jiang, H.; Gökce, B.; Marzun, G.; Kallio, T. Catalyst Support Effect on the Activity and Durability of Magnetic Nanoparticles: toward Design of Advanced Electrocatalyst for Full Water Splitting. ACS Appl. Mater. Interfaces 2018, 10, 31300-31311.
(8) Wu, G.; Johnston, C. M.; Mack, N. H.; Artyushkova, K.; Ferrandon, M.; Nelson, M.; Lezama-Pacheco, J. S.; Conradson, S. D.; More, K. L.; Myers, D. J.; Zelenay, P. Synthesis-structureperformance correlation for polyaniline- $\mathrm{Me}-\mathrm{C}$ non-precious metal cathode catalysts for oxygen reduction in fuel cells. J. Mater. Chem. 2011, 21, 11392-11405.

(9) Dicks, A. L. The role of carbon in fuel cells. J. Power Sources 2006, 156, 128-141.

(10) Sharma, S.; Pollet, B. G. Support materials for PEMFC and DMFC electrocatalysts-A review. J. Power Sources 2012, 208, 96119.

(11) Yarlagadda, V.; Carpenter, M. K.; Moylan, T. E.; Kukreja, R. S.; Koestner, R.; Gu, W.; Thompson, L.; Kongkanand, A. Boosting Fuel Cell Performance with Accessible Carbon Mesopores. ACS Energy Lett. 2018, 3, 618-621.

(12) Park, J.; Nabae, Y.; Hayakawa, T.; Kakimoto, M.-a. Highly Selective Two-Electron Oxygen Reduction Catalyzed by Mesoporous Nitrogen-Doped Carbon. ACS Catal. 2014, 4, 3749-3754.

(13) Proietti, E.; Jaouen, F.; Lefêvre, M.; Larouche, N.; Tian, J.; Herranz, J.; Dodelet, J.-P. Iron-based cathode catalyst with enhanced power density in polymer electrolyte membrane fuel cells. Nat. Commun. 2011, 2, No. 416.

(14) Liang, H.-W.; Wei, W.; Wu, Z.-S.; Feng, X.; Müllen, K. Mesoporous Metal-Nitrogen-Doped Carbon Electrocatalysts for Highly Efficient Oxygen Reduction Reaction. J. Am. Chem. Soc. 2013, 135, 16002-16005.

(15) Ding, J.; Wang, P.; Ji, S.; Wang, H.; Linkov, V.; Wang, R. Ndoped mesoporous $\mathrm{FeN}_{\mathrm{x}}$ /carbon as ORR and OER bifunctional electrocatalyst for rechargeable zinc-air batteries. Electrochim. Acta 2019, 296, 653-661.

(16) Ding, J.; Ji, S.; Wang, H.; Linkov, V.; Gai, H.; Liu, F.; Liu, Q.; Wang, R. N-Doped 3D Porous Ni/C Bifunctional Electrocatalysts for Alkaline Water Electrolysis. ACS Sustainable Chem. Eng. 2019, 7, 3974-3981.

(17) Shao, Y.; Yin, G.; Zhang, J.; Gao, Y. Comparative investigation of the resistance to electrochemical oxidation of carbon black and carbon nanotubes in aqueous sulfuric acid solution. Electrochim. Acta 2006, 51, 5853-5857.

(18) Antolini, E.; Gonzalez, E. R. Ceramic materials as supports for low-temperature fuel cell catalysts. Solid State Ionics 2009, 180, 746763.

(19) Hu, C.; Liu, D.; Xiao, Y.; Dai, L. Functionalization of graphene materials by heteroatom-doping for energy conversion and storage. Prog. Nat. Sci.: Mater. Int. 2018, 28, 121-132.

(20) Yang, L.; Jiang, S.; Zhao, Y.; Zhu, L.; Chen, S.; Wang, X.; Wu, Q.; Ma, J.; Ma, Y.; Hu, Z. Boron-Doped Carbon Nanotubes as MetalFree Electrocatalysts for the Oxygen Reduction Reaction. Angew. Chem. 2011, 123, 7270-7273.

(21) Yang, Z.; Yao, Z.; Li, G.; Fang, G.; Nie, H.; Liu, Z.; Zhou, X.; Chen, Xa.; Huang, S. Sulfur-Doped Graphene as an Efficient Metalfree Cathode Catalyst for Oxygen Reduction. ACS Nano 2012, 6, 205-211.

(22) Jin, J.; Pan, F.; Jiang, L.; Fu, X.; Liang, A.; Wei, Z.; Zhang, J.; Sun, G. Catalyst-Free Synthesis of Crumpled Boron and Nitrogen CoDoped Graphite Layers with Tunable Bond Structure for Oxygen Reduction Reaction. ACS Nano 2014, 8, 3313-3321.

(23) Davodi, F.; Tavakkoli, M.; Lahtinen, J.; Kallio, T. Straightforward synthesis of nitrogen-doped carbon nanotubes as highly active bifunctional electrocatalysts for full water splitting. J. Catal. 2017, 353, 19-27.

(24) Ma, T. Y.; Dai, S.; Jaroniec, M.; Qiao, S. Z. Graphitic Carbon Nitride Nanosheet-Carbon Nanotube Three-Dimensional Porous Composites as High-Performance Oxygen Evolution Electrocatalysts. Angew. Chem., Int. Ed. 2014, 53, 7281-7285.

(25) Yan, Z.; Ma, L.; Zhu, Y.; Lahiri, I.; Hahm, M. G.; Liu, Z.; Yang, S.; Xiang, C.; Lu, W.; Peng, Z.; Sun, Z.; Kittrell, C.; Lou, J.; Choi, W.; Ajayan, P. M.; Tour, J. M. Three-Dimensional Metal-GrapheneNanotube Multifunctional Hybrid Materials. ACS Nano 2013, 7, 5864. 


\section{[Electronic Supporting Information]}

\section{Mesoporous Single-Atom-Doped Graphene-Carbon Nanotube Hybrid: Synthesis and Tunable Electrocatalytic Activity for Oxygen Evolution and Reduction Reactions}

Mohammad Tavakkoli, ${ }^{1, *}$ Emmanuel Flahaut, ${ }^{2}$ Pekka Peljo, ${ }^{3}$ Jani Sainio, ${ }^{1}$ Fatemeh Davodi, ${ }^{4}$ Egor V. Lobiak, ${ }^{5}$ Kimmo Mustonen, ${ }^{6}$ Esko I. Kauppinen ${ }^{1}$

1 Department of Applied Physics, Aalto University School of Science, P.O. Box 15100, FI-00076 Aalto, Finland

2 CIRIMAT, Université de Toulouse, CNRS, INPT, UPS, UMR CNRS-UPS-INP N5085, Université Toulouse 3 Paul Sabatier, Bât. CIRIMAT, 118, route de Narbonne, 31062 Toulouse cedex 9, France

3 Research group of Physical Electrochemistry and Electrochemical Physics, Department of Chemistry and Material Sciences, Aalto University School of Chemical Engineering, P.O. Box 16100, FI-00076 Aalto, Finland.

4 Department of Chemistry and Material Sciences, Aalto University School of Chemical Engineering, P.O. Box 16100, FI-00076 Aalto, Finland.

5 Nikolaev Institute of Inorganic Chemistry, SB RAS, 630090 Novosibirsk, Russia

6 Faculty of Physics, University of Vienna, 1090 Vienna, Austria

*To whom correspondence should be addressed:

M. Tavakkoli (email: mohammad.tavakkoli@aalto.fi) 


\section{Experimental section}

\section{Chemical and chemical Characterizations:}

\section{Elemental Analysis}

Organic elemental microanalysis for $\mathrm{C}, \mathrm{H}$ and $\mathrm{N}$ elements was performed by combustion of the sample at $1050^{\circ} \mathrm{C}$ in a flux of $\mathrm{He} / \mathrm{O}_{2}$. Carbon and hydrogen were transformed into $\mathrm{CO}_{2}$ and water, respectively, separated using a chromatographic column, and measured using a thermal conductivity detector. The uncertainty was $0.50 \%$ for carbon, $0.30 \%$ for nitrogen and $0.20 \%$ for hydrogen. Oxygen content was measured by total pyrolysis of the sample at $1080^{\circ} \mathrm{C}$ in an $\mathrm{N}_{2}$ flux. Oxygen in pyrolysis compounds is transformed into $\mathrm{CO}$ by treatment with activated carbon at $1120^{\circ} \mathrm{C}$, and $\mathrm{CO}$ is then detected by IR spectroscopy. The uncertainty of the measurement was $0.30 \%$. This elemental analysis resulted in relative abundances of 90.8, 2.2, and $0.3 \mathrm{wt} \%$ for $\mathrm{C}$, O, and $\mathrm{N}$, respectively, in the N-Co-Mo-GF/CNT sample.

For the determination of metal content, the samples were wet mineralized ${ }^{1}$ and analyzed by inductively coupled plasma atomic emission spectroscopy (ICP-AES) (CREALINS) with an uncertainty of $2 \%$. The ICP-AES revealed 4.96 and $1.65 \mathrm{wt} \%$ of Co and Mo, respectively, in the NCo-Mo-GF/CNT catalyst.

\section{Gas adsorption}

The full adsorption/desorption isotherm of nitrogen was obtained using a Micromeritics TriStar II 3020 after degassing the sample $1 \mathrm{~h}$ at $90^{\circ} \mathrm{C}$ and then $10 \mathrm{~h}$ at $120^{\circ} \mathrm{C}$.

\section{Electron microscopy}

For transmission electron microscopy (TEM) and scanning TEM (STEM) characterizations, the catalyst material was dispersed in ethanol $(0.01 \mathrm{mg} / \mathrm{ml})$ and a $2 \mu 1$ droplet of the solution was cast on a carbon-coated TEM grid and dried in ambient air. The TEM observations were conducted in a JEOL-2200FS double Cs-corrected high-resolution microscope at an acceleration voltage of $200 \mathrm{kV}$.

The STEM analysis was conducted in an aberration-corrected Nion UltraSTEM100 microscope in Vienna, operated at an acceleration voltage of $60 \mathrm{kV}$ with the sample in a $5 \times 10^{-10} \mathrm{mbar}$ vacuum. The images were acquired with a medium angle annular dark field (MAADF) detector, except for Figure S2, which was acquired with a high angle (HAADF) detector. The respective semiangles were 60$200 \mathrm{mrad}$ and 80-300 mrad. To reduce the influence of probe tails and to decrease the detector noise, 
some images were pre-processed with a double Gaussian filtering procedure. ${ }^{2}$ Where necessary, the image contrast was further improved by applying the ImageJ lookup table "fire". The impurity atoms were identified with electron energy loss spectroscopy (EELS). The acquisition setup consisted of a Gatan PEELS 666 spectrometer retrofitted with an Andor iXon 897 electron-multiplying chargecoupled device camera (for details of the method, see ref. ${ }^{3-4}$ ).

\section{Raman Analysis}

The Raman spectra of N-Co-Mo-GN/CNT and Co-Mo-GN/CNT were measured with a $633 \mathrm{~nm}$ excitation laser. Five spectra were measured at different places on the samples, and their average $\mathrm{I}_{\mathrm{D}} / \mathrm{I}_{\mathrm{G}}$ ratio was calculated. The reported spectra are those in which the $\mathrm{I}_{\mathrm{D}} / \mathrm{I}_{\mathrm{G}}$ ratio was closest to the average value.

\section{XPS Analysis}

X-ray photoelectron spectroscopy (XPS) was carried out using a Kratos Axis Ultra spectrometer with monochromated $\mathrm{Al} \mathrm{Ka-radiation,} \mathrm{pass} \mathrm{energy} \mathrm{of} 40 \mathrm{eV}$, X-ray power of 150-225 $\mathrm{W}$ and an analysis area of approximately $700 \mu \mathrm{m} \times 300 \mu \mathrm{m}$. The deconvolutions of the XPS spectra were carried out in CasaXPS. The nitrogen 1s region was deconvoluted using Gaussian peaks with positions fixed to within $\pm 0.1 \mathrm{eV}$ of given values, and the full width at half-maximum (FWHM) restricted to be equal. However, the broader N-oxide peak was restricted to positions between 403 and $405 \mathrm{eV}$ with the FWHM restricted to below $4.5 \mathrm{eV}$. The deconvolution of the Co $2 \mathrm{p} 3 / 2$ peak was performed as done previously by Biesinger et al. ${ }^{5} \mathrm{CoO}$ parameters have been used for $\mathrm{Co}(\mathrm{II})$ but the spectra for different $\mathrm{Co}(\mathrm{II})$ compounds, such as $\mathrm{Co}(\mathrm{OH})_{2}$ and $\mathrm{CoOOH}$, are rather similar. In the deconvolution of the Mo $3 \mathrm{~d}$ region, an asymmetric CasaXPS line shape $\operatorname{LA}(1.1,2.3,2)$ was used for $\operatorname{Mo}(0)$ and the default GL(30) line shape was used for other peaks. For Co and Mo the peak positions were fixed to within $\pm 0.1 \mathrm{eV}$ of values in the literature. ${ }^{5-6}$

To transfer the N-Co-Mo-GF/CNT catalyst after ORR/OER measurements over the Ni substrate onto an $\mathrm{Au}$ substrate for the XPS measurements, the electrode was first immersed in deionized water to wash the excess electrolyte from the catalyst film. Then, before the film dried, it was detached from the substrate using a scalpel. Then, the free-standing catalyst film floating in the water was transferred on an Au substrate. 


\section{Scanning Electrochemical Microscopy (SECM) Analysis}

All the electrochemical measurements were performed at ambient temperature $\left(20 \pm 2{ }^{\circ} \mathrm{C}\right)$ under aerobic conditions in a Faraday cage with a CHI900 electrochemical workstation (CH Instruments, Austin, USA). A homemade glass-insulated Pt microelectrode (diameter $=10 \mu \mathrm{m}, \mathrm{RG}=8$ ) was used for all measurements, while a saturated calomel electrode and a Pt mesh were used as reference and working electrodes. Ni or GC electrodes (geometric surface area of $0.196 \mathrm{~cm}^{2}$ ) were used as substrate electrodes, and the catalyst was deposited on the substrate as described in the Electrochemical Procedures section for the preparation of the samples for electrochemical measurements. After deposition of the catalyst, approximately one third of the catalyst layer was removed to enable simultaneous study of the catalyst layer and the underlying substrate electrode. Approach curves were recorded at a rate of $1 \mu \mathrm{m} \mathrm{s}^{-1}$ with a $0.2 \mu \mathrm{m}$ step, with the Pt tip potential set to $0.3 \mathrm{~V} v s$ RHE to allow diffusion-limited reduction of dissolved oxygen. The oxygen reduction current on the Pt tip was give time to stabilize ${ }^{7}$ before beginning the approach. Once the tip was close to the substrate (typically normalized distance by the electrode radius $<1$ ), the substrate potential was scanned to the oxygen evolution region at a scan rate of $5 \mathrm{mV} \mathrm{s}^{-1}$, while keeping the SECM probe tip at a sufficiently negative potential $(0.3 \mathrm{~V}$ vs RHE) to allow the diffusion-controlled oxygen reduction, in substrate generation - tip collection mode.

\section{Electrochemical Procedures}

Electrocatalytic activity was investigated for the oxygen reduction and evolution reactions (ORR and OER) by rotating disk electrode (RDE) and by using a standard three-electrode system in $0.1 \mathrm{KOH}$. The reference and counter electrodes were a Standard Calomel Electrode, and an Iridium wire, respectively. Glassy carbon (GC, purchased from PINE Research), Ni (99.99\%, purchased from Goodfellow), and Au (99.99\% purchased from Goodfellow) were polished and used as the RDE working electrode tips with a similar geometric surface area of $0.196 \mathrm{~cm}^{2}$. The ORR and OER polarization curves were measured at a scan rate of $5 \mathrm{mV} \mathrm{s}^{-1}$ in an $\mathrm{O}_{2}$-saturated electrolyte. The OER electrochemical measurements were carried out at a rotation of $1600 \mathrm{rpm}$, while the ORR measurements were measured at various rotation rates (400, 700, 1200, 1600, 2000, and $2500 \mathrm{rpm})$. The ORR polarization curves were obtained in an $\mathrm{O}_{2}$-saturated electrolyte and were corrected by subtracting background current measured under identical conditions in an $\mathrm{N}_{2}$-saturated electrolyte to exclusively analyze the ORR current. ${ }^{8}$ The catalyst inks were drop cast onto the different substrates with a similar loading of $\sim 0.2 \mathrm{mg} \mathrm{cm}^{-2}$ and dried in air. Subsequently, $25 \mu \mathrm{l}$ of $5 \mathrm{wt} \%$ Nafion was diluted with $1 \mathrm{ml}$ of ethanol and $5 \mu \mathrm{l}$ of that solution was added on top of the catalyst layers as a binder. Before any measurements were taken, the electrodes were cycled 50 cycles at between 0 and 
$1.2 \mathrm{~V}$ versus RHE at a $50 \mathrm{mV} \mathrm{s}^{-1}$ scan rate to stabilize the electrochemical response of the catalysts. The uncompensated ohmic electrolyte resistance $\left(R_{u}\right)$ used for the $i R$ correction was determined using electrochemical impedance measurements by equating $R_{u}$ to the minimum total impedance in a nonFaradaic region measured between $10 \mathrm{~Hz}$ and $100 \mathrm{kHz}$, where the capacitive and inductive impedances are negligible and the phase angle was near zero.

\section{Measurement of the kinetic current density and the number of transferred in the ORR}

The kinetic current and the number of electrons involved per $\mathrm{O}_{2}$ in the ORR on the catalysts were calculated based on the Koutecky-Levich equation:

$$
1 / j=1 / j_{k}+1 / j_{l}=1 / j_{k}+1 / \mathrm{B} \omega^{1 / 2}
$$

where $j$ is the experimentally measured current density, $j_{k}$ is the kinetic current density, $j_{l}$ is the diffusion-limited current density, and $\omega$ is the electrode rotating rate. The diffusion limiting current equals $\mathrm{B} \omega^{1 / 2}$ and $\mathrm{B}$ was calculated from the slope of the Koutecky-Levich $(\mathrm{K}-\mathrm{L})$ plots based on the Levich equation:

$$
\mathrm{B}=0.2 \mathrm{nF}\left(\mathrm{Do}_{2}\right)^{2 / 3} v^{-1 / 6} \mathrm{Co}_{\mathrm{O}}
$$

where $\mathrm{n}$ represents the number of transferred electrons per oxygen molecule, $\mathrm{F}$ is the Faraday constant $\left(\mathrm{F}=96485 \mathrm{C} \mathrm{mol}^{-1}\right), \mathrm{Do}_{2}$ is the diffusion coefficient of $\mathrm{O}_{2}$ in $0.1 \mathrm{M} \mathrm{KOH}\left(1.9 \times 10^{-5} \mathrm{~cm}^{2} \mathrm{~s}^{-1}\right), v$ is the kinetic viscosity $\left(0.01 \mathrm{~cm}^{2} \mathrm{~s}^{-1}\right)$, and $\mathrm{C}_{\mathrm{O} 2}$ is the bulk concentration of $\mathrm{O}_{2}$ in $0.1 \mathrm{M} \mathrm{KOH}\left(1.2 \times 10^{-6} \mathrm{~mol}\right.$ $\mathrm{cm}^{-3}$ ). The constant 0.2 is used when the rotation speed is stated in rpm. The number of transferred electrons per $\mathrm{O}_{2}$ was calculated by Equation (2) where B equals the inverse of the slope of linear $\mathrm{K}-$ L plots. 

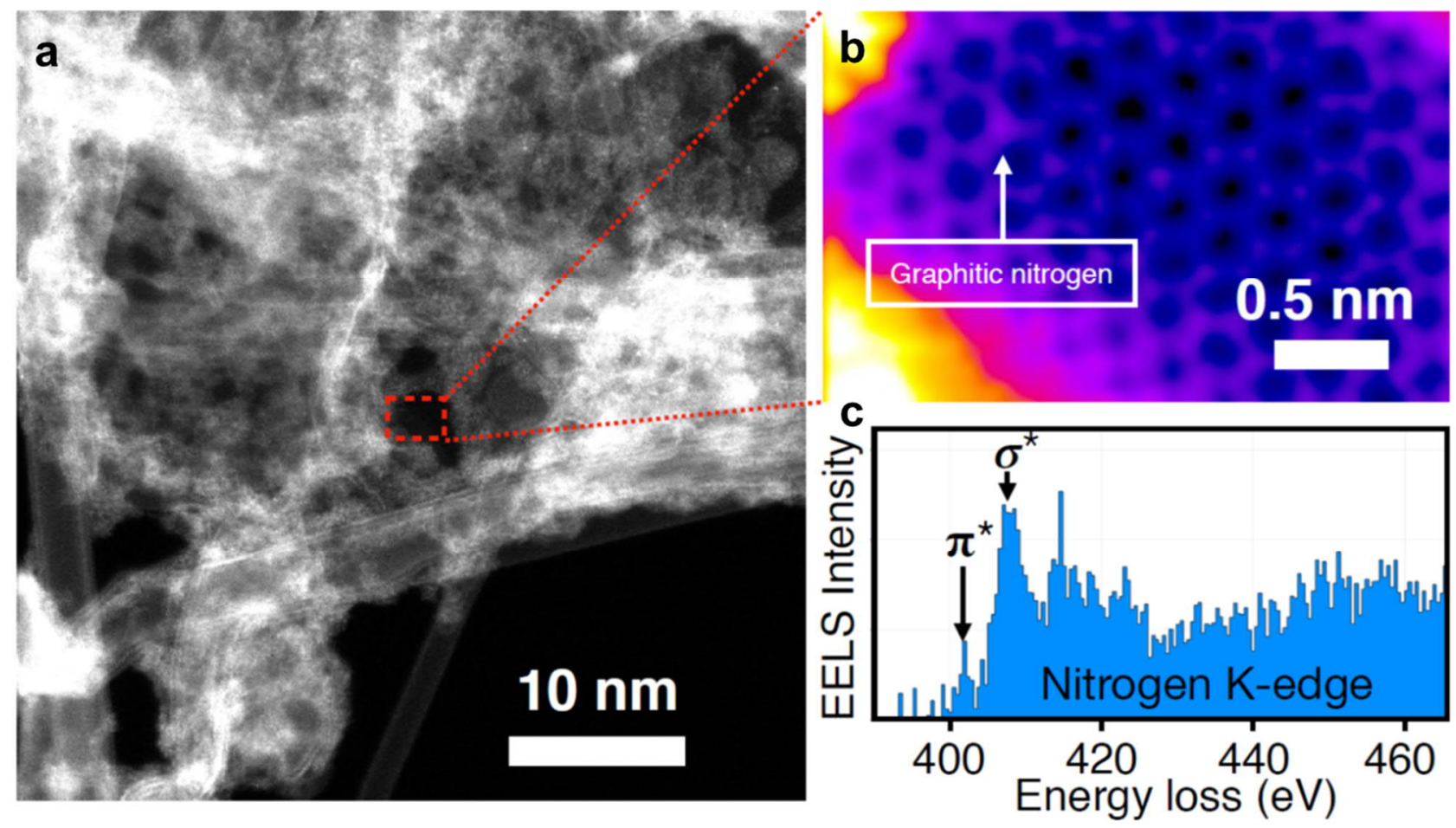

Figure S1. (a) A STEM image of the N-Co-Mo-GF/CNT sample; (b) A high-resolution STEM image of a graphene monolayer, showing a nitrogen heteroatom substitution and (c) the corresponding EELS spectrum which confirms the presence of the $\mathrm{N}$ heteroatom in the graphitic lattice. 

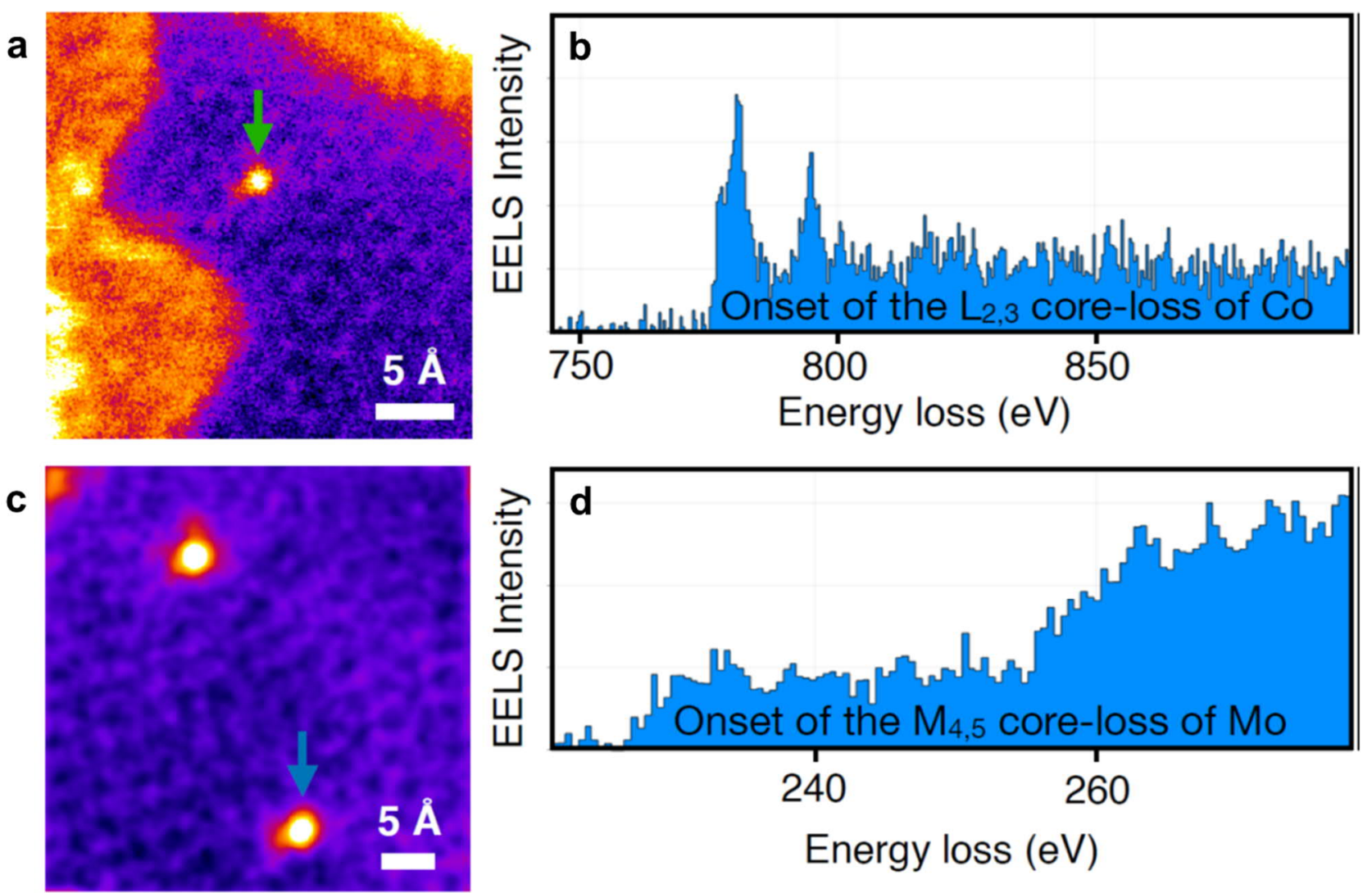

Figure S2. (a) High-resolution STEM image of a Co atom in a graphene layer in the N-Co-Mo-GF/CNT sample with (b) the corresponding EELS map, confirming the presence of single-atom Co in the graphitic lattice. (c) High-resolution STEM image of a Mo atom in a graphene layer in the N-Co-Mo-GF/CNT sample with (d) the corresponding EELS spectra, confirming the presence of single-atom Mo in the graphitic lattice. 

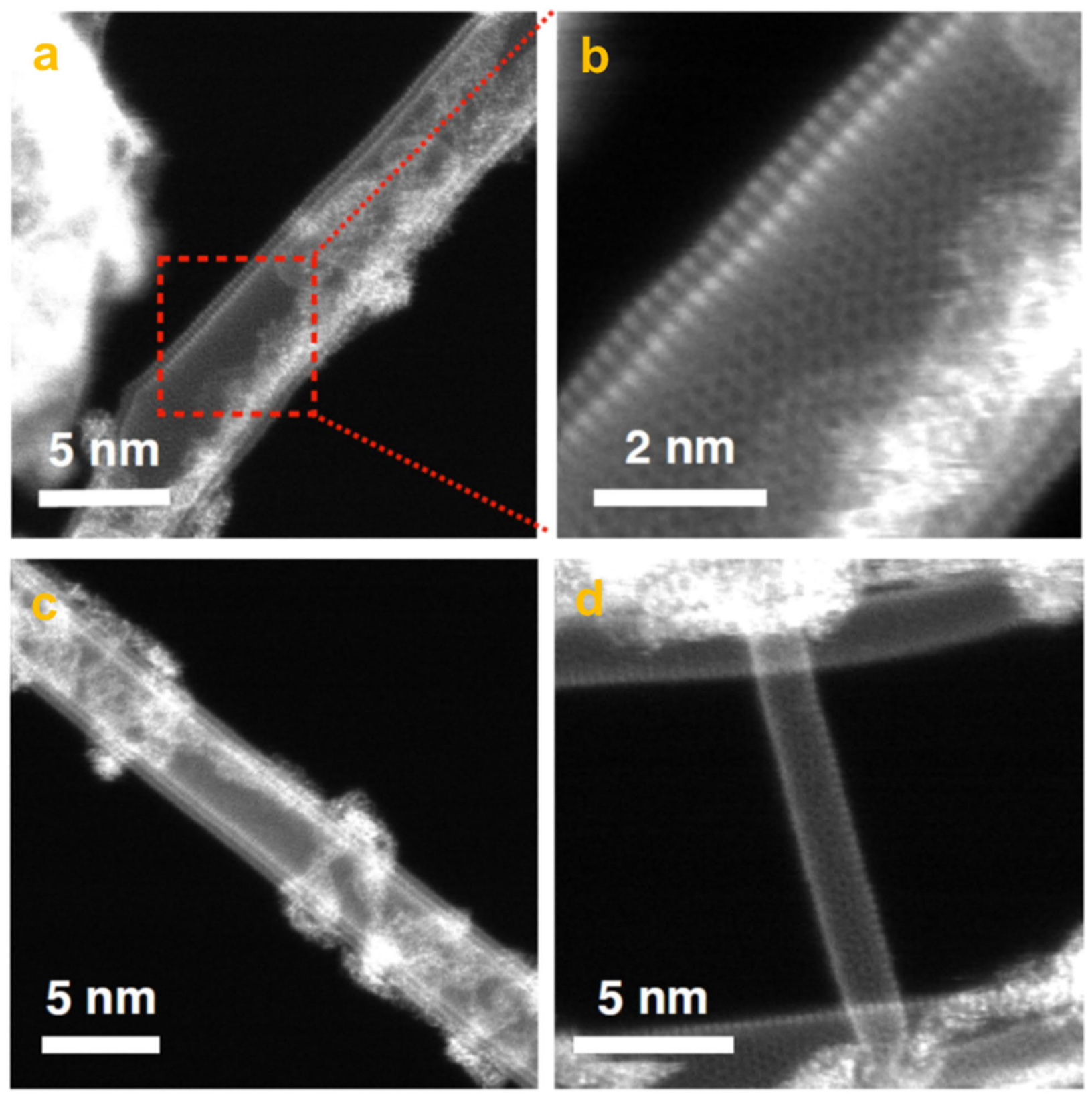

Figure S3. High-resolution STEM image of the main types of CNTs observed: (a and b) double-walled CNTs, (c) a triple-walled CNT, and (d) a single-walled CNT in the N-Co-Mo-GF/CNT sample. The atomic resolution of the images does not show the presence of metallic single-atoms (Co and Mo) in the CNTs, but these are detected in graphene nanoflakes in the N-Co-Mo-GF/CNT sample. 


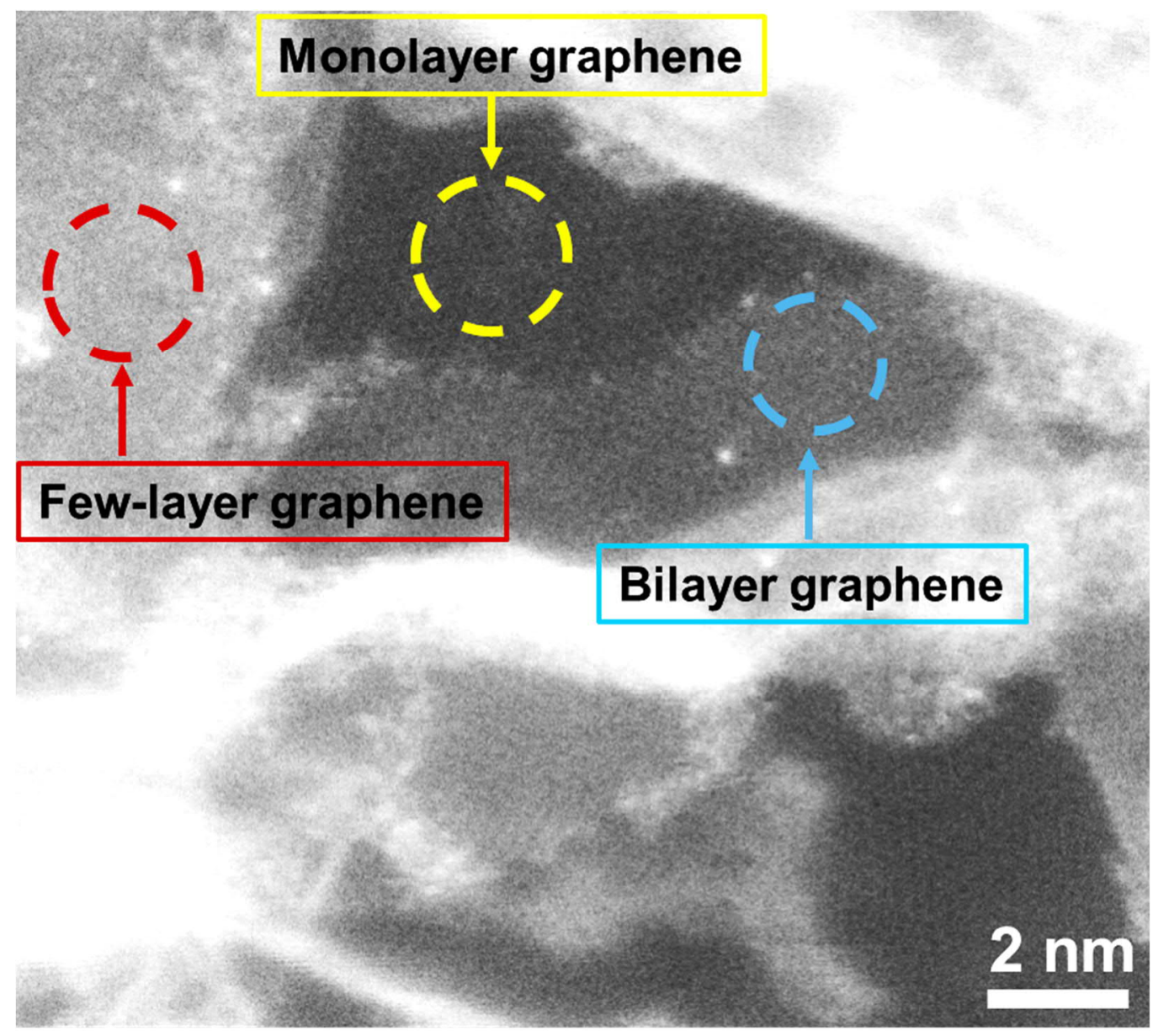

Figure S4. STEM image of graphene nanoflakes, showing the presence of monolayer, bilayer, and few-layer graphene in the N-Co-Mo-GF/CNT hybrid material. The bilayer and few-layer graphene are discriminated based on their contrast difference with the monolayer graphene. 

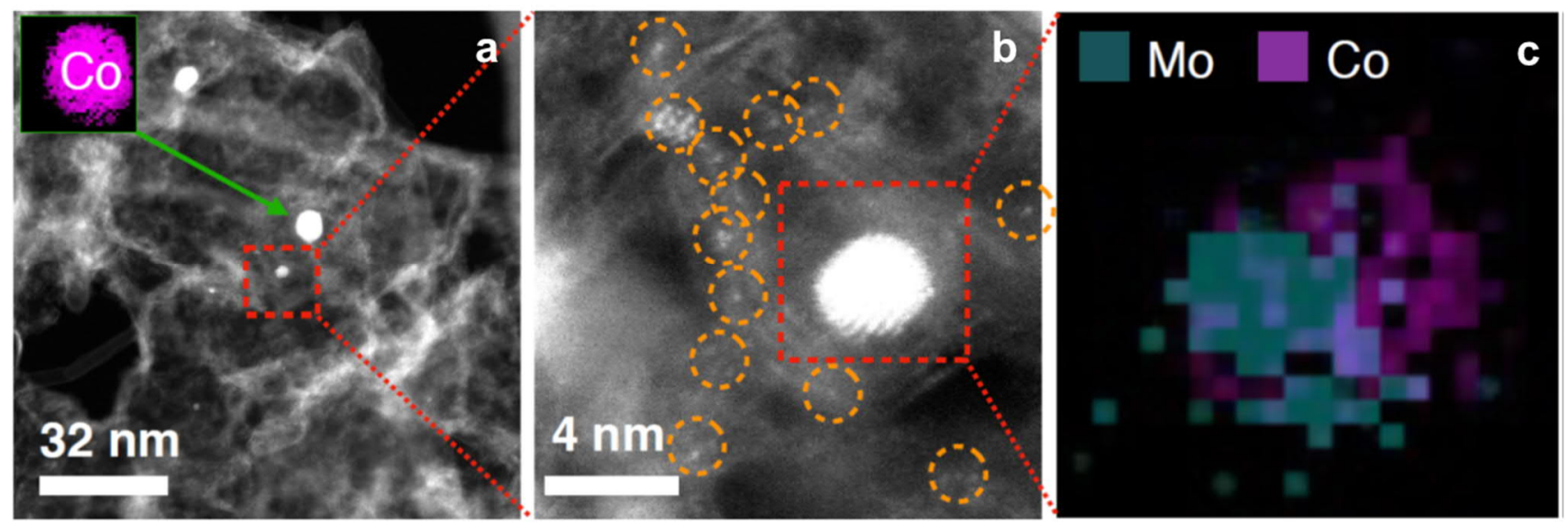

Figure S5. (a) STEM image of N-Co-Mo-GF/CNT. The inset shows the EELS map of a Co particle on the sample. (b) A high-resolution STEM image of the area indicated in sub-panel (a), showing that the density of single-atom dopants is significantly higher than the density of nanoparticles in the N-Co-Mo-GF/CNT sample.

(c) The EELS map of a bimetallic (Co and Mo) nanoparticle obtained from the indicated area in sub-panel (b). 

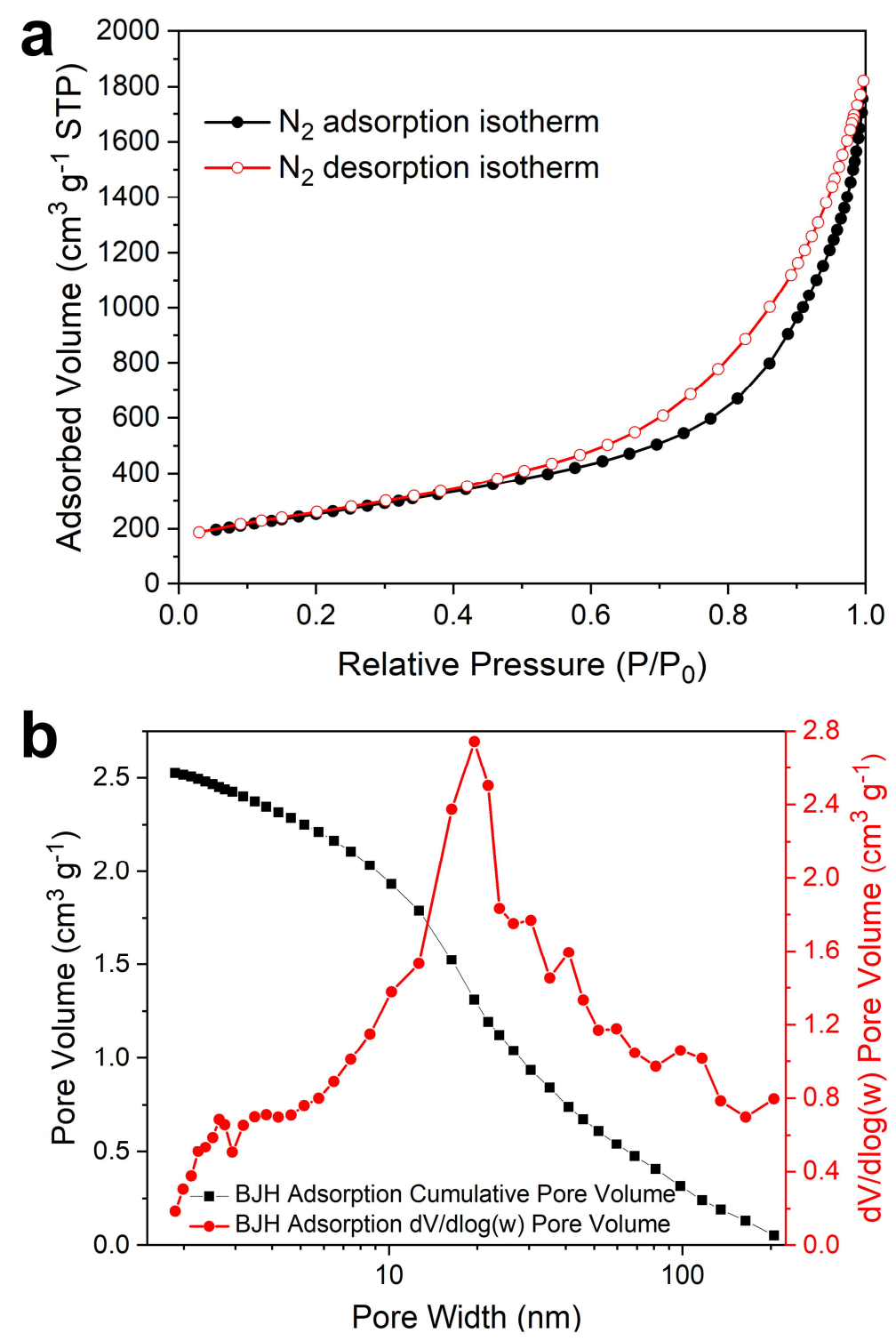

Figure S6. (a) $\mathrm{N}_{2}$ adsorption (solid black dots) and desorption (open red dots) isotherms at $77 \mathrm{~K}$. (b) Cumulative pore volume and pore size distribution obtained using the $\mathrm{BJH}$ method from the adsorption branch of the $\mathrm{N}_{2}$ isotherm. 


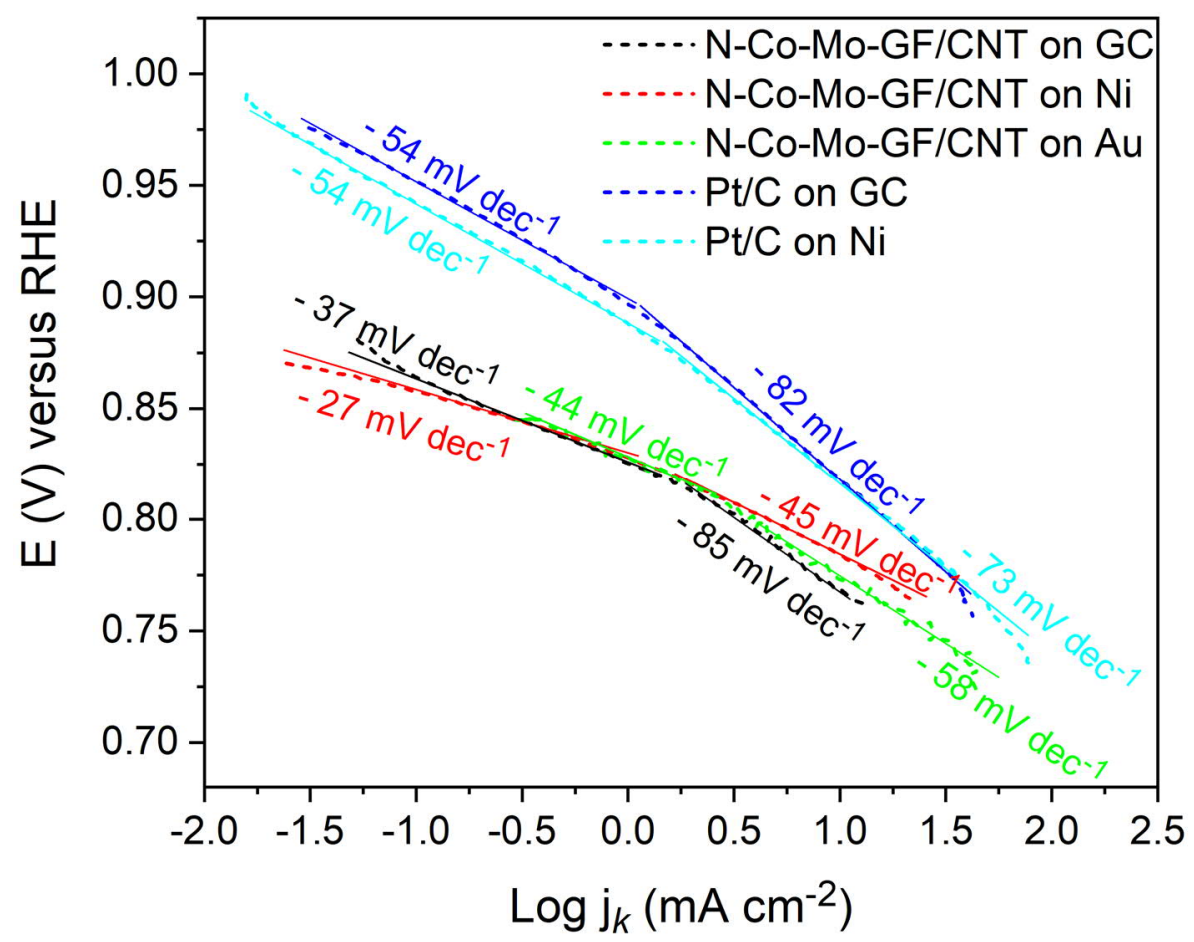

Figure S7. ORR Tafel plots of N-Co-Mo/GF/CNT on GC (black), Ni (red), and Au (green), as well as Pt/C on GC (blue), and Ni (cyan). 

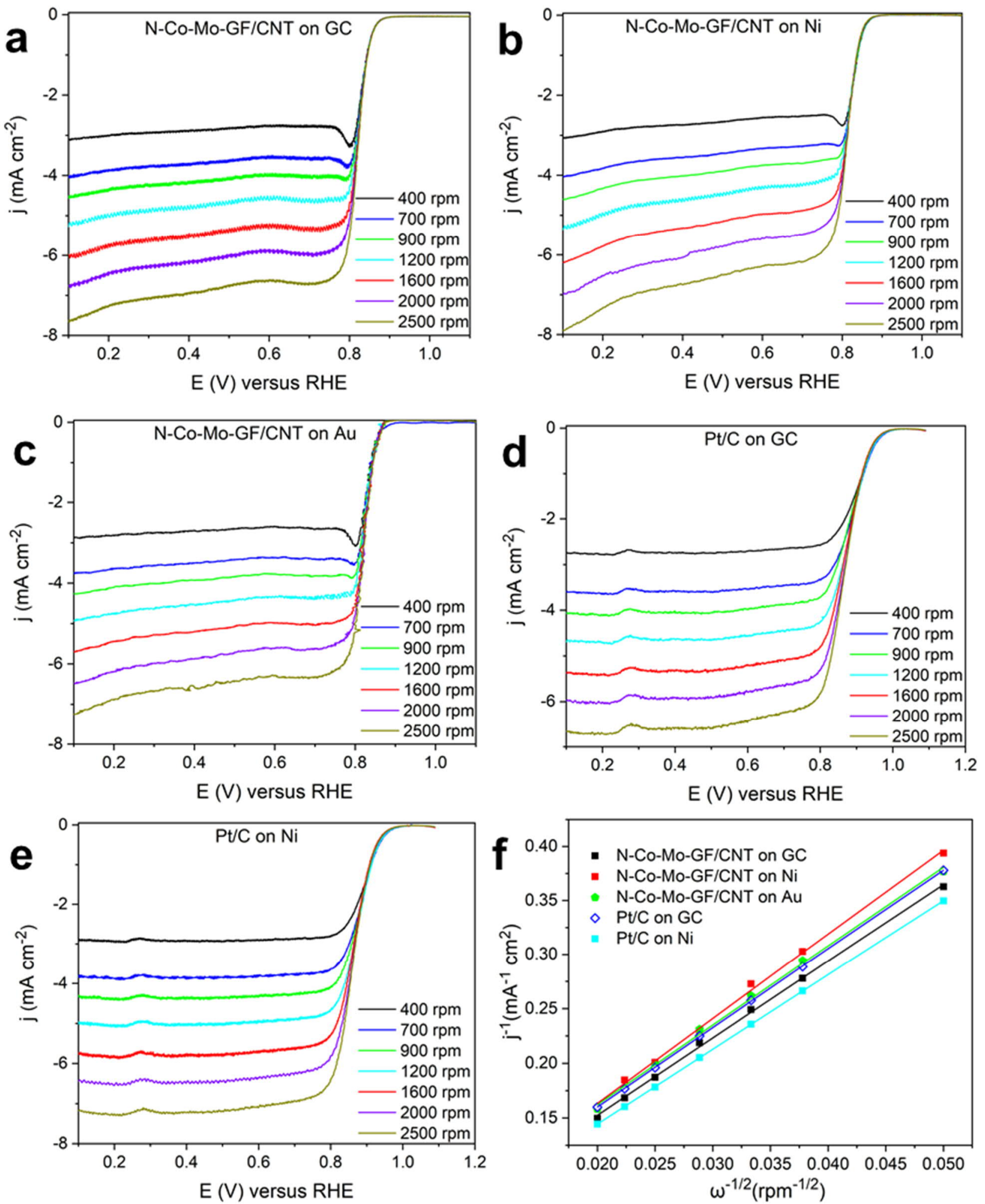

Figure S8. ORR polarization curves obtained at 400 (black lines), 700 (blue lines), 900 (green lines), 1200 (cyan lines), 1600 (red lines), 2000 (violet lines), and 2500 (dark yellow lines) rpm for N-Co-Mo/GF/CNT on (a) GC, (b) Ni, and (c) Au substrates, as well as for Pt/C on (d) GC, and (e) Ni substrates. (f) K-L plots at 0.7 V for N-Co-Mo-GF/CNT on GC (black), Ni (red), and Au (green), as well as for Pt/C on GC (blue), and Ni (cyan) substrates. 


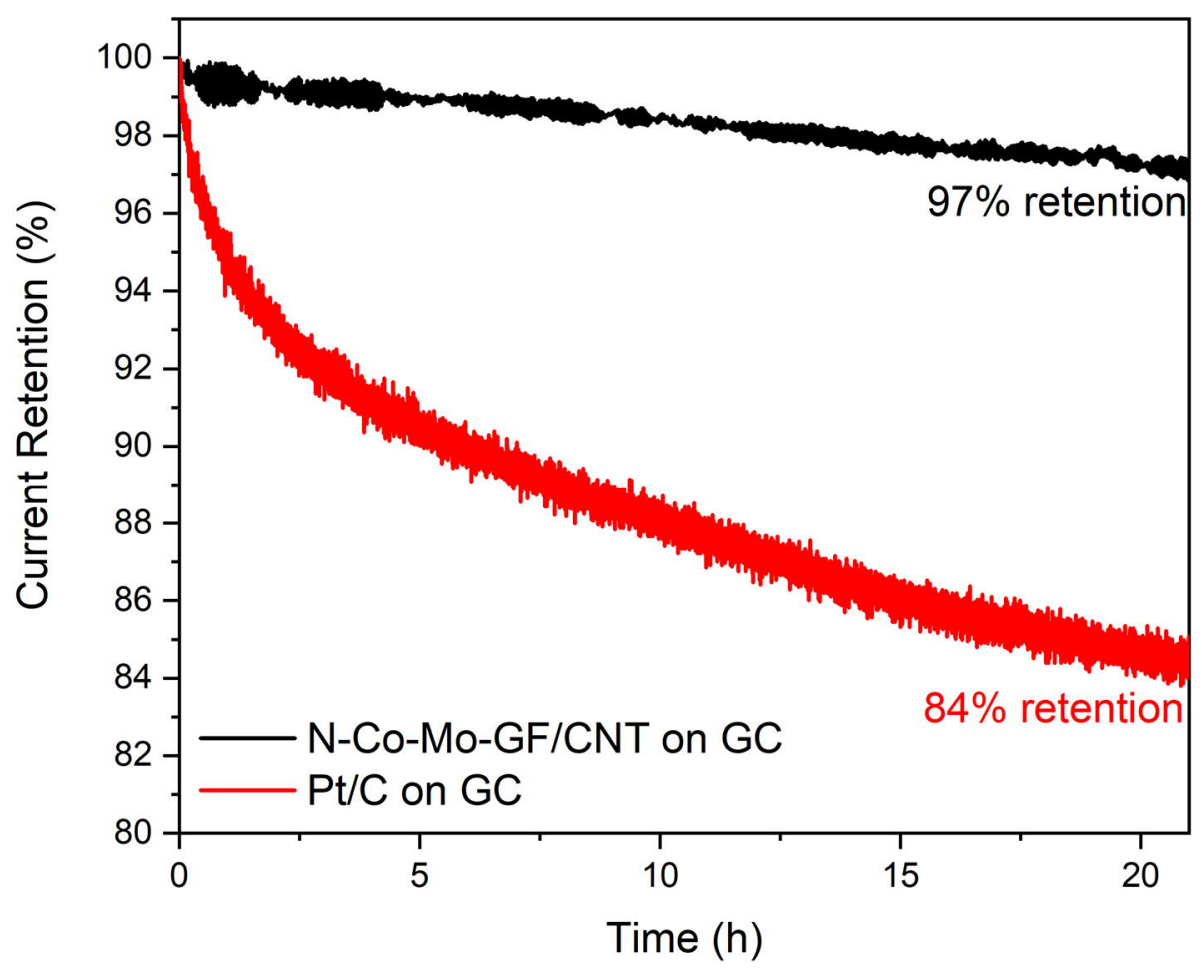

Figure S9. ORR chronoamperometry measurements at $0.7 \mathrm{~V}$ ss RHE obtained for N-Co-Mo-GF/CNT and $\mathrm{Pt} / \mathrm{C}$ deposited on a glassy carbon (GC) substrate. 


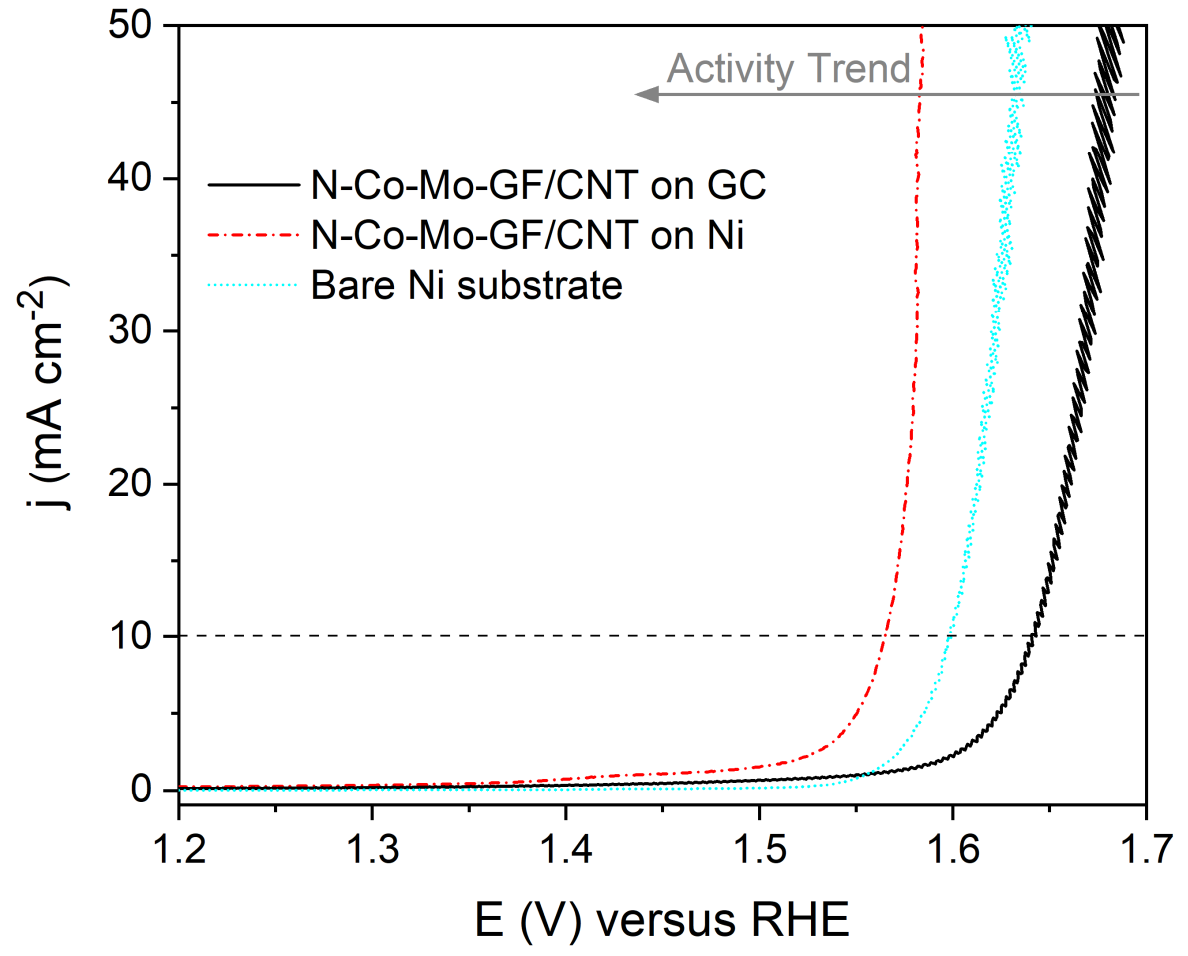

Figure S10. OER polarization curves of N-Co-Mo-GF/CNT on GC and Ni substrates compared to that of a bare Ni substrate, indicating the synergistic effect between the Ni substrate and the N-Co-MoGF/CNT electrocatalyst for enhancing OER activity. The polarization curves were obtained in a $0.1 \mathrm{M}$ $\mathrm{KOH}$ solution at a scan rate of $5 \mathrm{mV} \mathrm{s}^{-1}$ and $1600 \mathrm{rpm}$ rotation speed. 


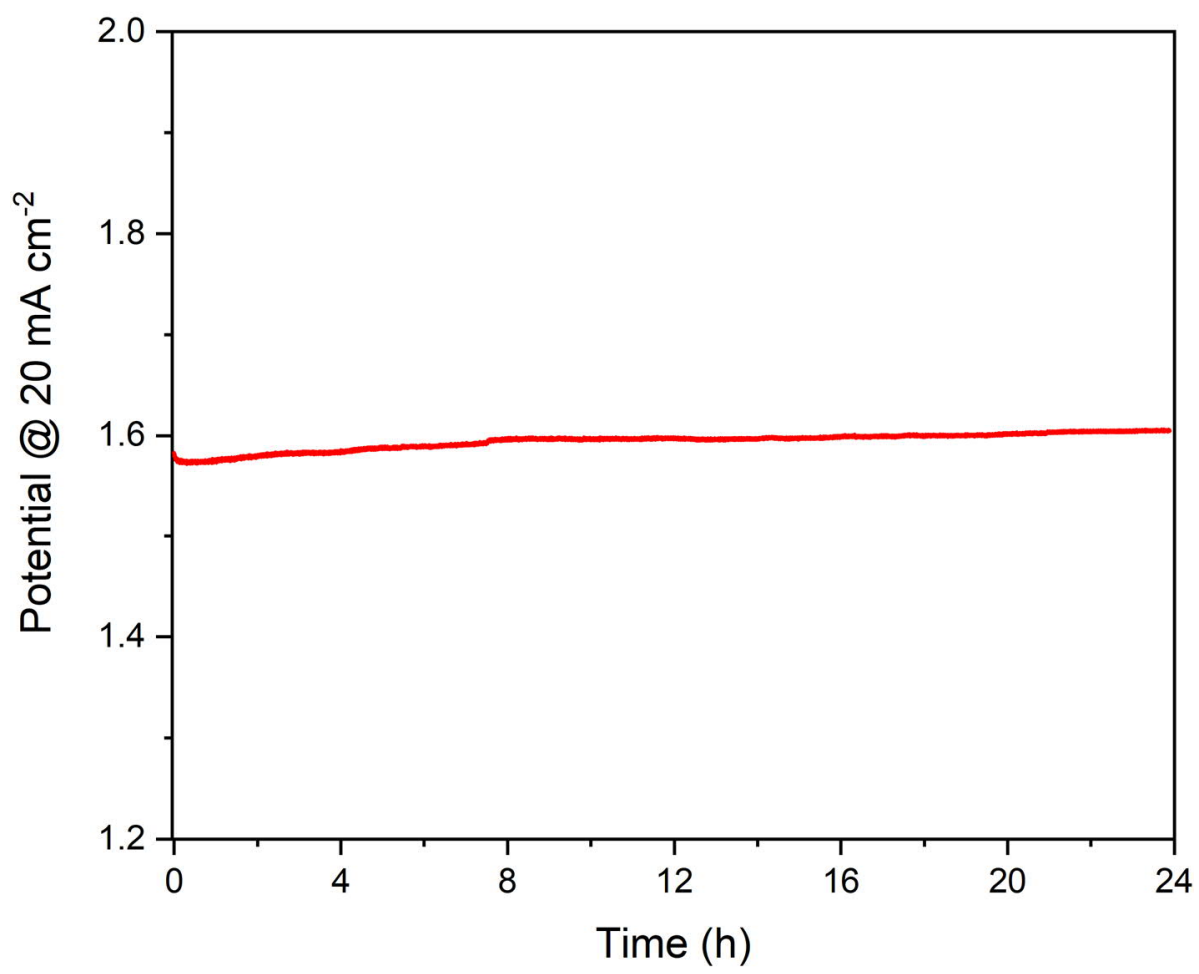

Figure S11. OER chronopotentiometry measurement at $20 \mathrm{~mA} \mathrm{~cm}^{-2}$ obtained for $\mathrm{N}-\mathrm{Co}-\mathrm{Mo}-\mathrm{GF} / \mathrm{CNT}$ deposited on the Ni substrate. 

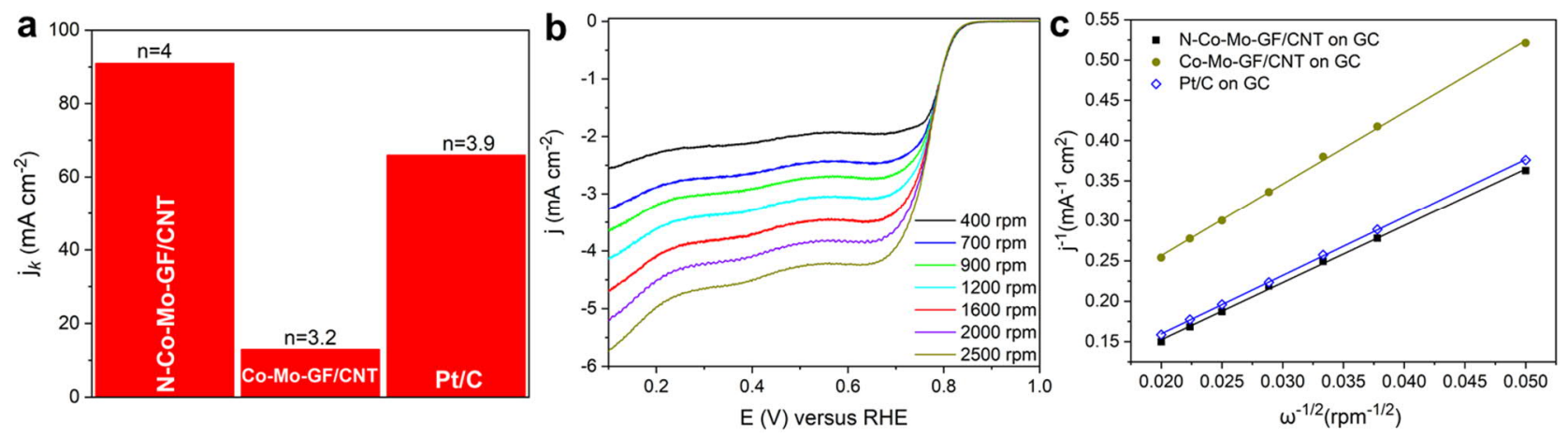

Figure S12. Effect of $\mathrm{N}$ heteroatoms on the ORR activity of the N-Co-Mo-GF/CNT electrocatalyst. (a) ORR kinetic current densities obtained from Co-Mo-GF/CNT (dark yellow), N-Co-Mo-GF/CNT, (black), and Pt/C (blue); (b) RDE ORR polarization curves of the Co-Mo-GF/CNT measured at 400 (black line), 700 (blue line), 900 (green line), 1200 (cyan line), 1600 (red line), 2000 (violet line), and 2500 (dark yellow line) rpm; (c) KL plot of Co-Mo-GF/CNT (dark yellow) compared to that of N-Co-Mo-GF/CNT (black), and Pt/C (blue). All the plots were obtained in an $\mathrm{O}_{2}$-saturated $0.1 \mathrm{M} \mathrm{KOH}$ solution. The electrocatalysts were deposited on a GC substrate. 


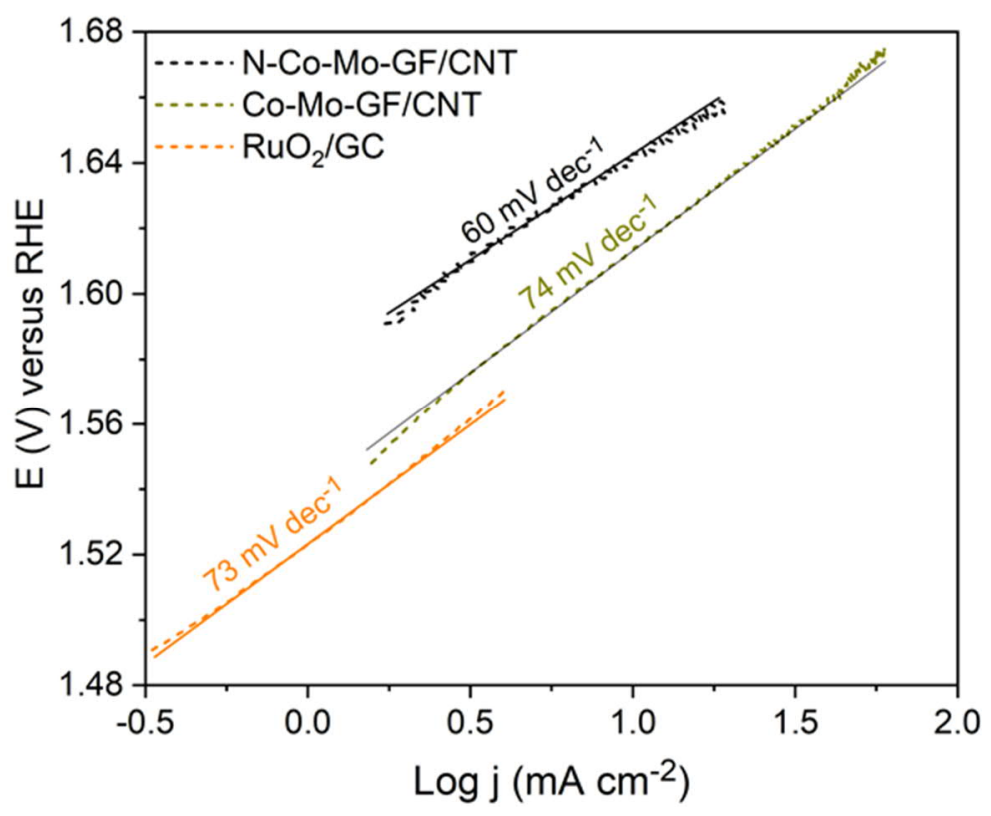

Figure S13. OER Tafel plots of Co-Mo-GF/CNT compared to that of N-Co-Mo-GF/CNT and $\mathrm{RuO}_{2}$ in a $0.1 \mathrm{M} \mathrm{KOH}$ solution. The electrocatalysts were deposited on a GC substrate. 


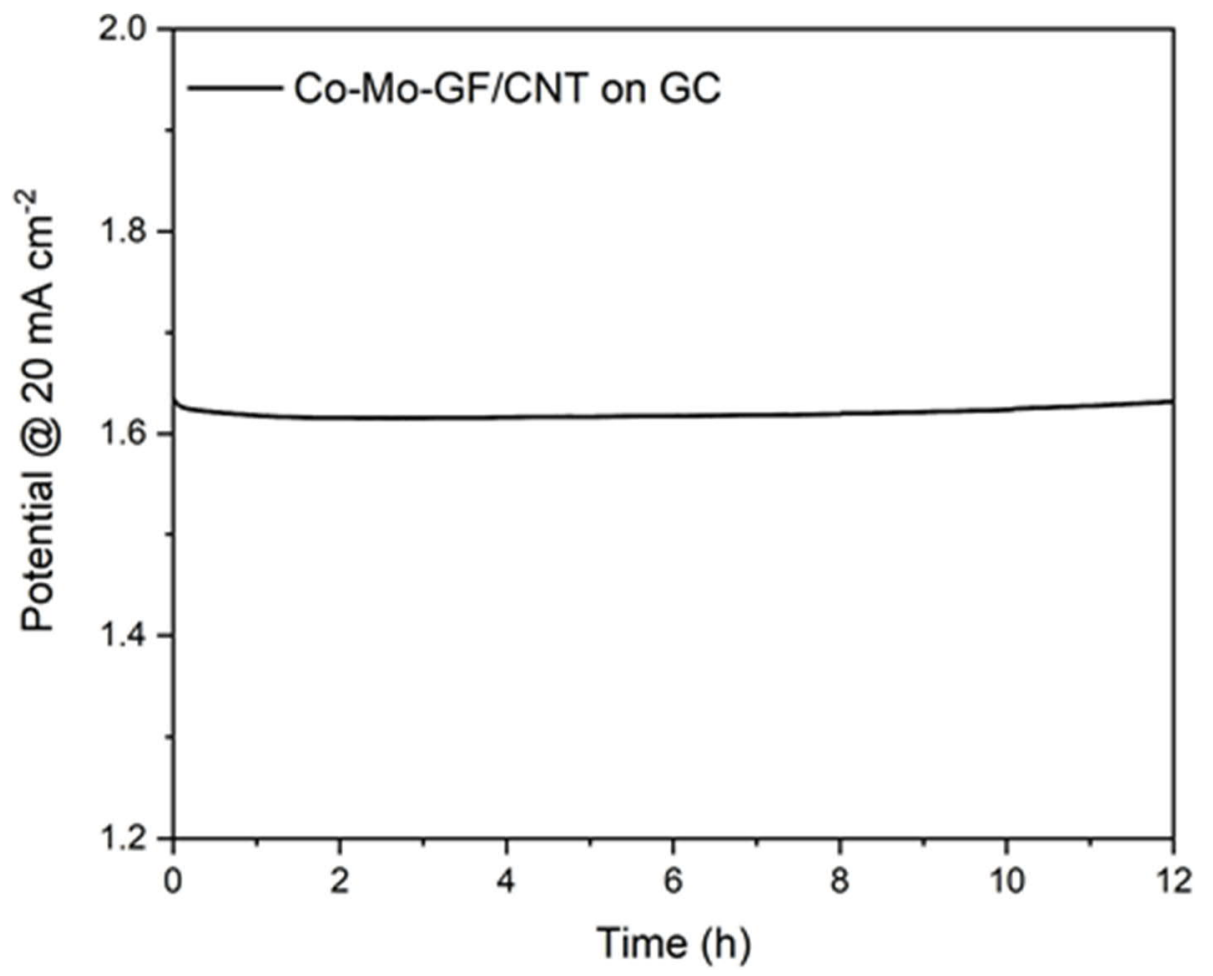

Figure S14. ORR chronopotentiometry measurement at $20 \mathrm{~mA} \mathrm{~cm}{ }^{-2}$ obtained for Co-Mo-GF/CNT deposited on a GC substrate. 


\section{X-ray photoelectron spectroscopy (XPS)}

Figure S15a shows the C 1s spectra in which a typical graphitic carbon peak is observed at about $284.4 \mathrm{eV}$. The $\mathrm{O}$ 1s spectrum in Figure S15b for the pristine sample shows a rather broad feature mainly consisting of two components at roughly $532 \mathrm{eV}$ and $534 \mathrm{eV}$ related to $\mathrm{C}=\mathrm{O}$ and $\mathrm{C}-\mathrm{O}$ bonds (also possibly from $\mathrm{OH}$-groups) respectively, ${ }^{9}$ and a shoulder peak at roughly $530.5 \mathrm{eV}$ which could be related to $\mathrm{MoO}_{3}$ observed in the Mo 3d spectrum. After the electrochemical measurements, this peak related to $\mathrm{MoO}_{3}$ was no longer observed in the sample. Figure S15c shows the photoelectron survey spectra of the pristine sample and after the ORR and OER measurements. In the sample taken after the electrochemical measurements in $0.1 \mathrm{M} \mathrm{KOH}$ solution, potassium $2 \mathrm{p}$ peaks between $292 \mathrm{eV}$ and $298 \mathrm{eV}$ can also be seen. The atomic concentrations are given in Table S1.

To detect whether there was Ni diffusion from the Ni substrate into the N-Co-Mo-GF/CNT catalyst film during the OER measurements, the catalyst material was transferred from the Ni substrate onto an Au substrate after the OER measurements. XPS spectra detected no Ni in the catalyst film (Table $\mathrm{S} 1$ ), meaning that Ni did not diffuse from the substrate into the N-Co-Mo-GF/CNT catalyst during the electrochemical measurements. The higher detected amount of Co after the electrochemical measurements in Table S1 can be attributed to the removal of carbon layers surrounding Co nanoparticles during the OER. The graphene layers around the metal nanoparticles can be stripped off during the OER, ${ }^{10}$ so that less signal attenuation will be caused by the carbon encapsulation layers, and hence, more Co can be detected on the surface by XPS as a surface analysis technique.
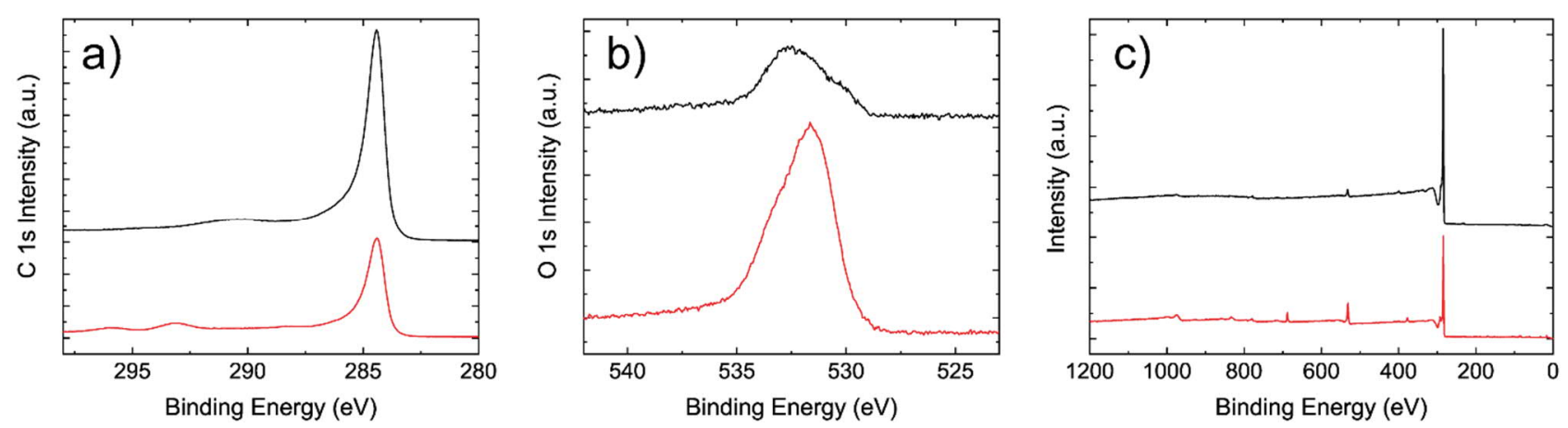

Figure S15. X-ray photoelectron spectra of the N-Co-Mo-GF/CNT electrocatalyst before (black) and after (red) the ORR and OER measurements on the Ni substrate: a) C 1s region, b) O 1s region and c) survey spectra. 
Table S1. The atomic percentages of elements in the pristine N-Co-Mo-GF/CNT sample and after ORR/OER measurements of the sample on the Ni substrate. The error associated with each value is roughly $\pm 10 \%$.

\begin{tabular}{lll}
\hline Element & pristine & After ORR and OER \\
\hline $\mathrm{C}(\%)$ & 97.1 & 82.3 \\
$\mathrm{O}(\%)$ & 1.6 & 11.1 \\
$\mathrm{~N}(\%)$ & 1.0 & 1.0 \\
$\mathrm{Co}(\%)$ & 0.13 & 0.53 \\
$\mathrm{Mo}(\%)$ & 0.08 & $0.02 *$ \\
$\mathrm{~F}(\%)$ & - & 2.5 \\
$\mathrm{~K}(\%)$ & - & 2.0 \\
$\mathrm{~S}(\%)$ & - & 0.53 \\
Impurities $<0.2$ at- $\%$ & $\mathrm{Cl}$ & $\mathrm{Cl}, \mathrm{Si}$ \\
\hline
\end{tabular}

*The amount of Mo was estimated roughly by peak fitting and removing the overlapping S $2 \mathrm{~s}$ peak 

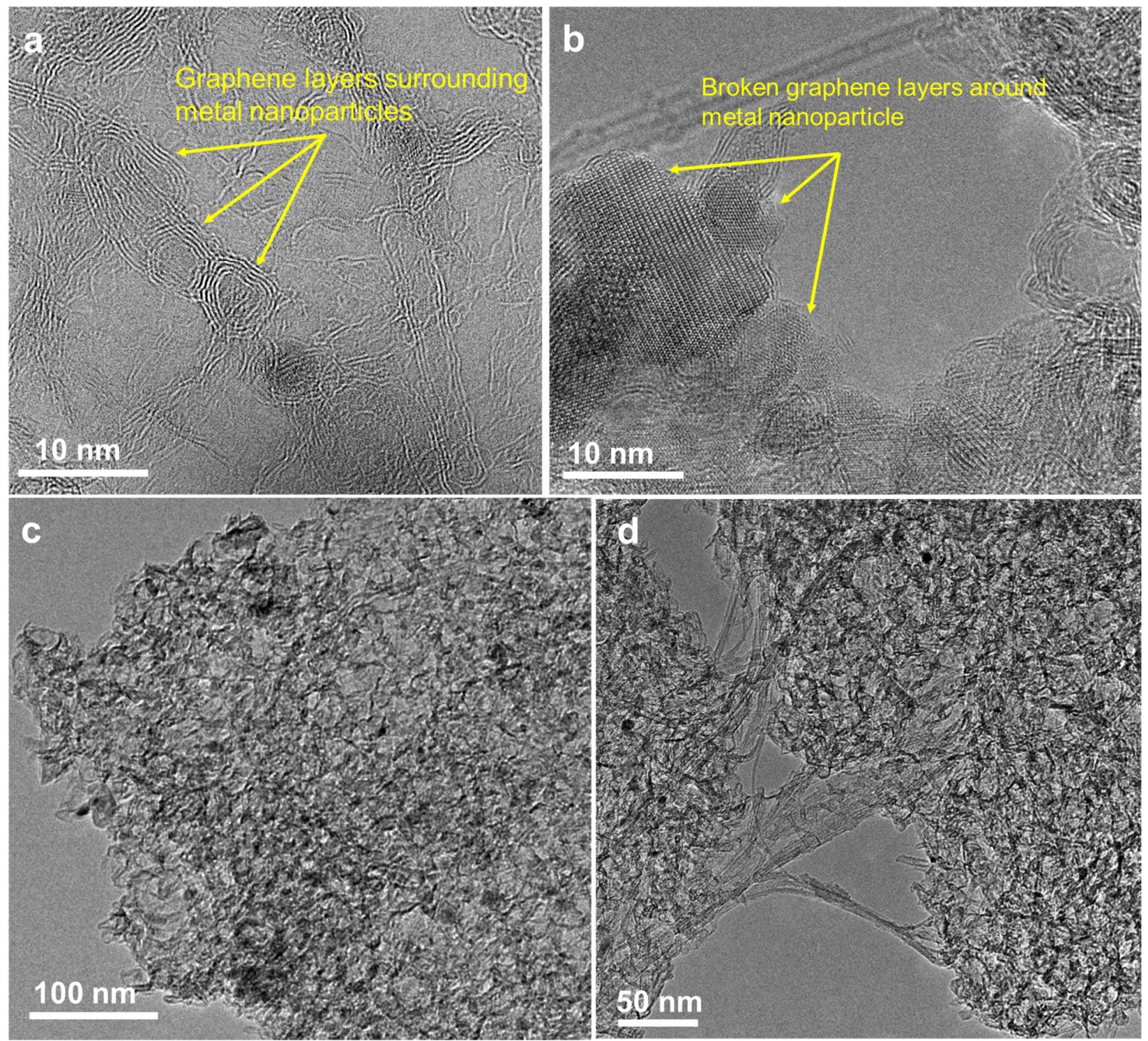

Figure S16. TEM images of N-Co-Mo-GF/CNT (a) before and (b-d) after ORR/OER measurements. Subpanel (b) shows that graphene layers surrounding the metal nanoparticles in sub-panel (a) are stripped off after the OER/ORR measurements. 


\section{Scanning Electrochemical Microscopy (SECM) Analysis}

\section{SECM simulations}

To analyze the experimental results, the approach curves were compared with the theoretical expressions for positive and negative feedbacks as described by Lefrou and Cornut. ${ }^{11}$ Numerical finite element simulations of the system were performed with the COMSOL Multiphysics software, v. 5.4, to qualitatively reproduce the experimental results. The catalyst layer was described as a porous electrode with a thickness of $20 \mu \mathrm{m}$. The different parameters used for the simulations are tabulated in Table S2. The simulations were performed in 2-D axis symmetry with a sufficiently large domain and mesh density to allow microelectrode limiting currents within $3 \%$ of the theoretical value to be obtained.

Table S2. Simulation parameters

\begin{tabular}{|l|c|c|}
\hline Parameter & Value & Notes \\
\hline Tip radius & $5 \mu \mathrm{m}$ & Experimental \\
\hline Radius of the insulating glass (RG) & $8 \times$ tip radius & Air-saturated solution \\
\hline Diffusion coefficient of oxygen & $1.93 \times 10^{-5} \mathrm{~cm}^{2} / \mathrm{s}$ & Assumption \\
\hline Oxygen concentration in $0.1 \mathrm{M} \mathrm{KOH}$ & $0.265 \mathrm{mM}$ & Liquid volume fraction, assumption \\
\hline Porosity of the catalyst layer & 0.3 & $\begin{array}{c}\text { Estimated from SECM } \\
\text { Gas volume fraction }\end{array}$ \\
\hline Thickness of the catalyst layer & 0.3 & $\begin{array}{c}\text { measurements between catalyst and } \\
\text { substrate covered parts }\end{array}$ \\
\hline
\end{tabular}

The effects of migration were assumed negligible, so "Transport of Diluted Species-physics" was utilized for the diffusion of all the species in the aqueous phase and "Transport of Diluted Species in Porous Media-physics" was utilized for the transfer of oxygen within the film. The distance of the tip to the substrate was varied with a parametric sweep, and the tip current was evaluated in the steadystate. The general diffusion equation for a species $i$ is:

$\frac{\partial c_{i}}{\partial t}+\nabla \cdot\left(-D_{i} \nabla c_{i}\right)=R_{i}$

where $c$ is concentration, $t$ is time, $D$ is the diffusion coefficient and $R$ is the reaction term for the species $i$. For steady-state simulations, the time derivate is zero. The species in the aqueous phase are $\mathrm{O}_{2}$ and $\mathrm{OH}^{-}$. The presence of excess of oxygen is modeled by assuming that $30 \%$ of the porous electrode is filled with liquid, and the same volume is taken up by gaseous $\mathrm{O}_{2}$. This oxygen is in equilibrium with dissolved oxygen: 
$\mathrm{O}_{2}(\mathrm{aq}) \underset{k_{-1}}{\stackrel{k_{1}}{\rightleftharpoons}} \mathrm{O}_{2}(\mathrm{~g})$

with the equilibrium constant

$$
K=\frac{c_{\mathrm{O}_{2}(\mathrm{~g})}}{c_{\mathrm{O}_{2}(\mathrm{aq})}}=\frac{k_{1}}{k_{-1}}
$$

where $k_{1}$ is the rate constant to transfer $\mathrm{O}_{2}$ from the aqueous phase into the gas phase and $k_{-1}$ is the rate constant for the inverse reaction. Note that here the oxygen may actually not be in the gas phase but adsorbed by the graphene nanoflakes and nanotubes. Within the electrode the reaction term for oxygen transfer from the gas phase to the aqueous phase is

$$
R_{\mathrm{O}_{2}(\mathrm{aq})}=-R_{\mathrm{O}_{2}(\mathrm{~g})}=k_{-1}\left[\mathrm{O}_{2}(\mathrm{~g})\right]-k_{1}\left[\mathrm{O}_{2}(\mathrm{aq})\right]
$$

Bruggeman relations were used to take into account the transport in the porous media. The following electrode reaction takes place at the Pt tip at the diffusion limited rate:

$$
\mathrm{O}_{2}(\mathrm{aq})+2 \mathrm{H}_{2} \mathrm{O}+4 e^{-} \longrightarrow 4 \mathrm{OH}^{-}(\mathrm{aq})
$$

i.e. the surface concentration of $\mathrm{O}_{2}(\mathrm{aq})$ at the tip is 0 . The flux of $\mathrm{OH}^{-}$at this surface is then calculated from eq. S5 and the flux of $\mathrm{O}_{2}(\mathrm{aq})$ at the tip. The electrode/catalyst layer boundary is insulating for all species, and concentration boundary conditions of the bulk concentration are enforced at the outer boundaries of the geometry.

If oxygen is evolving in the porous electrode, the experimental data on the current are converted into the amount of oxygen being generated in the electrode, and an additional reaction term is added to take into account this generation of oxygen (and removal of $\mathrm{OH}^{-}$) in the inverse reaction of S5.

Figure S18 shows the simulated approach curves with different values of $K$ and $k_{-1}$. The first graph shows a comparison of the simulated curves for positive and negative feedbacks with the theoretical expressions of Lefrou and Cornut ${ }^{11}$ (dotted lines) for a flat substrate. As a reasonable agreement was found, the simulations done in this work are considered sufficiently accurate.

The presence of the porous electrode increased the currents observed even when both the partition coefficient and transfer rate coefficient were small. Overall, the simulations showed that a positive feedback type response was observed when a sufficient amount of additional $\mathrm{O}_{2}$ was present and the transfer rate between the aqueous and gas phase was fast enough. The maximum concentration of pure oxygen in air at a standard temperature and pressure is $45 \mathrm{mM}$ (as calculated from the molar 
volume of the gas, $22.4 \mathrm{~L} / \mathrm{mol}$ ). Therefore, the maximum partition coefficient for eq. S2 would be 170 for an air-saturated solution. On the other hand, the oxygen adsorption of carbon-based materials has been measured as $c a .1 \mathrm{mmol} / \mathrm{g},{ }^{12}$ hence, considering the amount of the catalyst $\left(0.2 \mathrm{mg} / \mathrm{cm}^{2}\right)$ and the layer thickness $(20 \mu \mathrm{m})$, the concentration of oxygen could reach $100 \mathrm{mM}$. This quantitative analysis indicates that partition coefficients of a couple of hundred are reasonable. The oxygen transfer rate between water and gas has never been reported, but all the earlier SECM experiments at a water/air interface ${ }^{13-14}$ describe this as an equilibrium reaction. Therefore, the reaction should be quite fast, and the rate constants of up to $10000 \mathrm{~s}^{-1}$ used in this work are reasonable. Furthermore, the amount of gas in the electrode could be tuned by tuning the volume fraction of the gas in the simulations, which here was arbitrarily 0.3. A larger volume fraction of gas would require smaller partition coefficients to result in the positive feedback type behavior observed experimentally. It should be noted that we do not know the exact state of the oxygen present in the catalyst layer, and therefore all the simulation results are qualitative. Nevertheless, the simulations show that the presence of oxygen can indeed explain the experimentally observed trends. Furthermore, simulations are able to show that once oxygen is removed from the catalyst layer, it is replaced over time by partitioning from the aqueous phase.

Next, the simulations of oxygen evolution on the catalysts were investigated. The experimental results showed that with an Ni substrate, it took much longer time for oxygen to reach the tip. If GC was used instead, the response was immediate, but also decayed much faster. This indicates that the evolved oxygen was retained in the catalyst layer with an Ni substrate, while with GC the release of oxygen was faster. To qualitatively study this effect, the diffusion distance of oxygen to the tip was varied from 20 to $500 \mu \mathrm{m}$ by increasing the thickness of the porous layer. In every case, the same amount of oxygen calculated from the experimental OER CV at $5 \mathrm{mV} \mathrm{s}^{-1}$ was generated. When the diffusion distance was small, the tip response was very fast, and the decay in the current was more rapid. When the diffusion distance increased, there was a longer lag time before oxygen reached the tip, leading to a similar response as observed experimentally on an Ni substrate. This indicates that on a GC substrate, oxygen evolution takes place close to the catalyst surface and/or the oxygen is released very fast from the catalyst layer. On the other hand, with an Ni substrate, oxygen evolution takes place deeper in the catalyst layer. As the catalyst activity was higher on the Ni substrate, this indicated that oxygen evolution actually took place at the interface of the Ni substrate and the catalyst. Some of the oxygen may also be entrapped in the film, and only slowly released from there. 

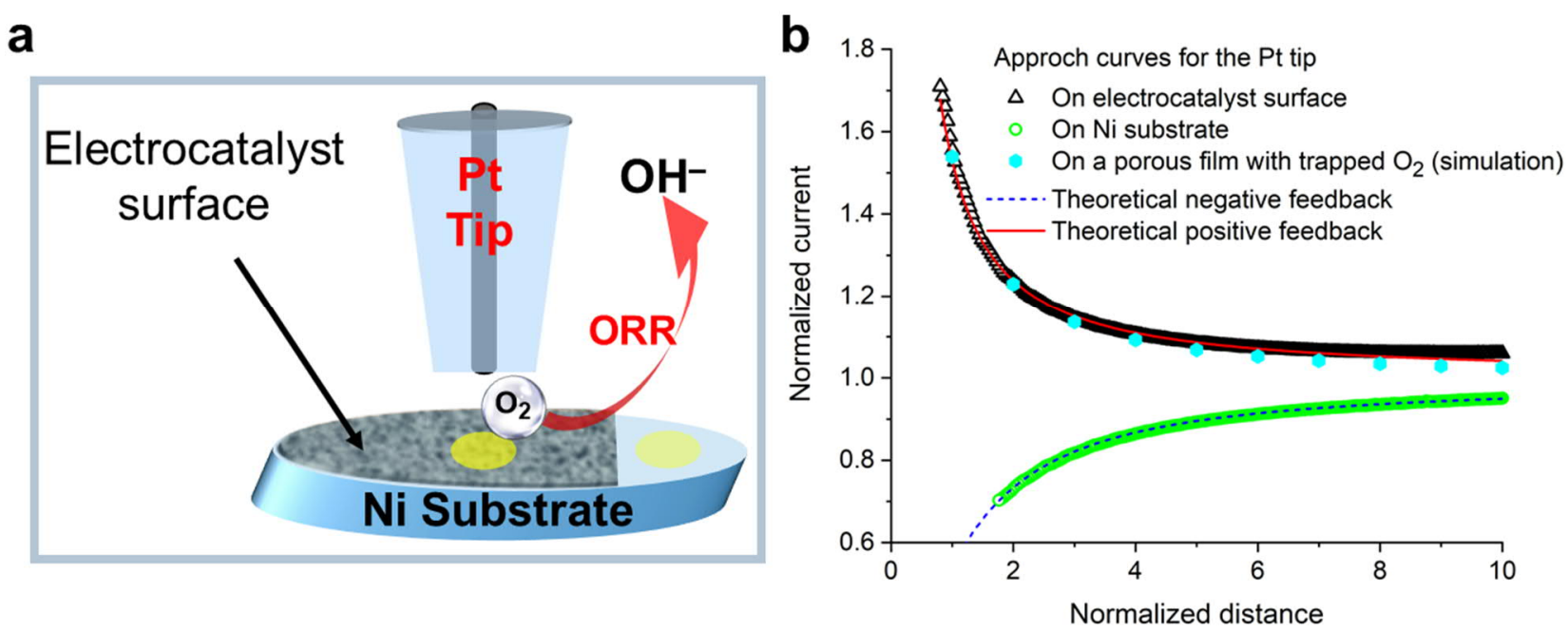

Figure S17. (a) Schematic representation of the SECM Pt tip approaching the substrate for observing the feedback from the electrocatalyst surface and the Ni substrate over which the catalyst is deposited. (b) Experimental, theoretical, and simulated approach curves on the N-Co-Mo-GF/CNT electrocatalyst layer and on the Ni surface. 


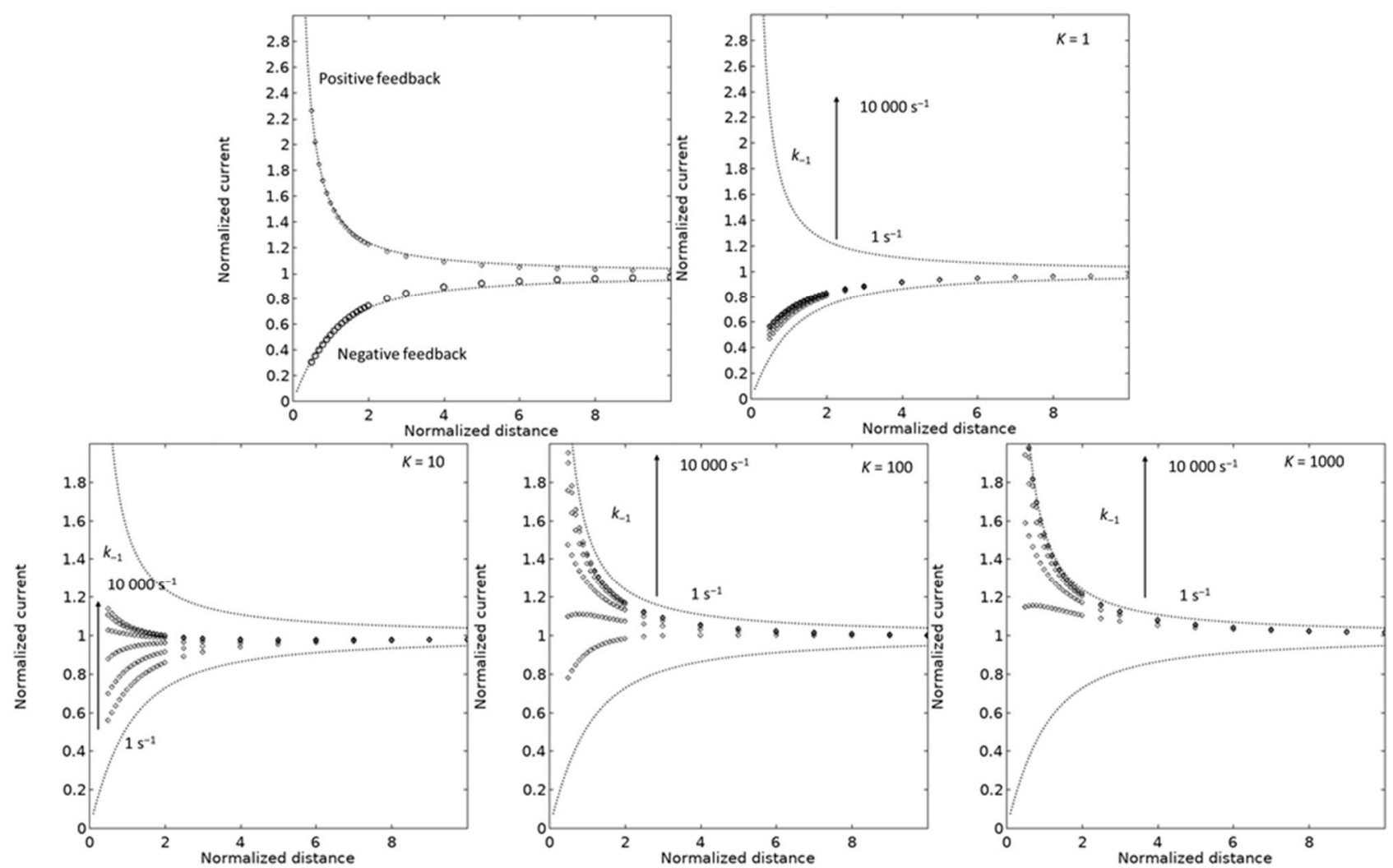

Figure S18. Simulated approach curves for different values of $K\left(1,10,100\right.$ and 1000) and $k_{-1}(1,10,100$, $1000,10000 \mathrm{~s}^{-1}$ ). Theoretical expressions of Lefrou and Cornut for both positive and negative feedbacks ${ }^{11}$ are shown for comparison (dotted lines). The first figure shows the simulated positive and negative feedbacks on a flat surface (open symbols), and the other figures show the tip approach curves on the porous catalyst layer. Distance from the surface is normalized by the electrode radius $(5 \mu \mathrm{m})$ and tip current is normalized by the current in the bulk. 

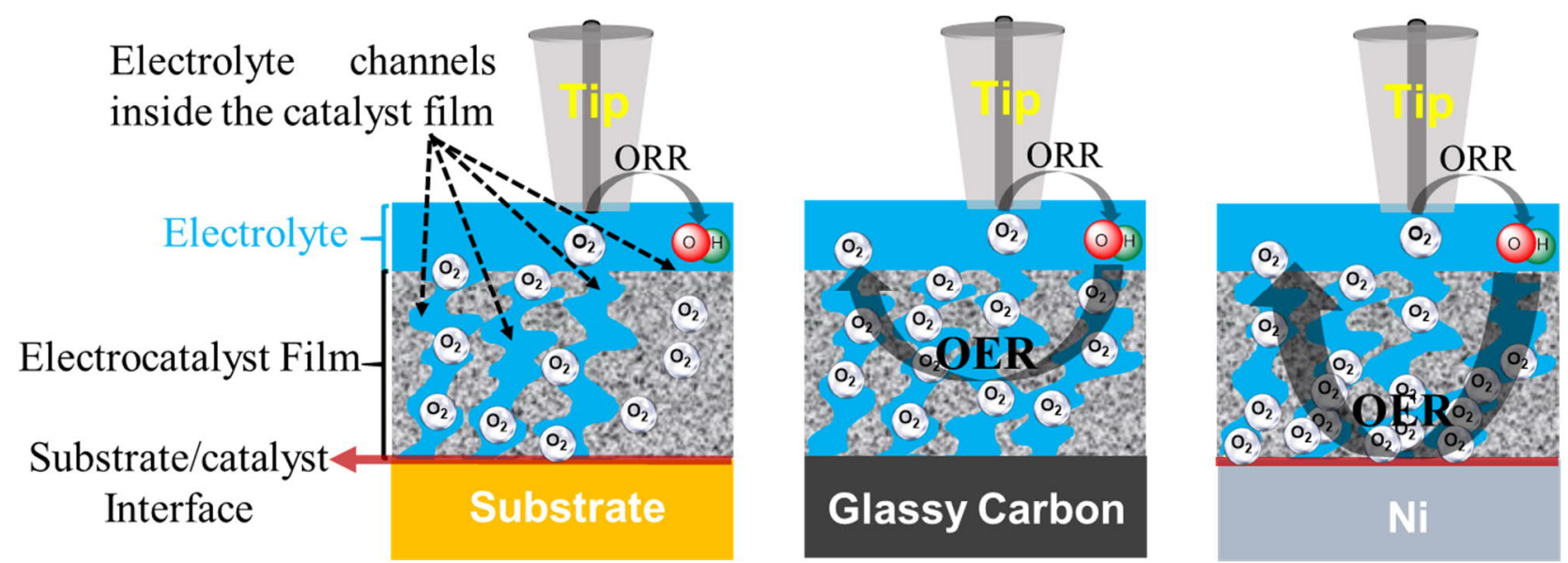

Scheme S1. A porous electrocatalyst layer containing oxygen results in an enhanced tip current. When glassy carbon is used as the substrate, the OER reaction takes place uniformly throughout the catalyst layer. When Ni is instead used, the new sites formed at the interface between the substrate and the catalyst, favoring OER at the substrate/catalyst interface. 


\section{References}

(1). Ayouni-Derouiche, L.; Méjean, M.; Gay, P.; Milliand, M.-L.; Lantéri, P.; Gauthier, L.; Flahaut, E., Development of efficient digestion procedures for quantitative determination of cobalt and molybdenum catalyst residues in carbon nanotubes. Carbon 2014, 80, 59-67.

(2). Krivanek, O. L.; Chisholm, M. F.; Nicolosi, V.; Pennycook, T. J.; Corbin, G. J.; Dellby, N.; Murfitt, M. F.; Own, C. S.; Szilagyi, Z. S.; Oxley, M. P.; Pantelides, S. T.; Pennycook, S. J., Atom-by-atom structural and chemical analysis by annular dark-field electron microscopy. Nature 2010, 464 (7288), 571-574.

(3). Inani, H.; Mustonen, K.; Markevich, A.; Ding, E.-X.; Tripathi, M.; Hussain, A.; Mangler, C.; Kauppinen, E. I.; Susi, T.; Kotakoski, J., Silicon Substitution in Nanotubes and Graphene via Intermittent Vacancies. J. Phys. Chem. C 2019, 123 (20), 13136-13140.

(4). Mustonen, K.; Markevich, A.; Tripathi, M.; Inani, H.; Ding, E.-X.; Hussain, A.; Mangler, C.; Kauppinen, E. I.; Kotakoski, J.; Susi, T., Electron-Beam Manipulation of Silicon Impurities in Single-Walled Carbon Nanotubes. Adv. Funct. Mater. O (0), 1901327.

(5). Biesinger, M. C.; Payne, B. P.; Grosvenor, A. P.; Lau, L. W. M.; Gerson, A. R.; Smart, R. S. C., Resolving surface chemical states in XPS analysis of first row transition metals, oxides and hydroxides: Cr, Mn, Fe, Co and Ni. Appl. Surf. Sci. 2011, 257 (7), 2717-2730.

(6). Baltrusaitis, J.; Mendoza-Sanchez, B.; Fernandez, V.; Veenstra, R.; Dukstiene, N.; Roberts, A.; Fairley, N., Generalized molybdenum oxide surface chemical state XPS determination via informed amorphous sample model. Appl. Surf. Sci. 2015, 326, 151-161.

(7). Steimecke, M.; Seiffarth, G.; Bron, M., In Situ Characterization of Ni and Ni/Fe Thin Film Electrodes for Oxygen Evolution in Alkaline Media by a Raman-Coupled Scanning Electrochemical Microscope Setup. Anal. Chem. 2017, 89 (20), 10679-10686.

(8). Gojković, S. L.; Zečević, S. K.; Savinell, R. F., O 2 Reduction on an Ink-Type Rotating Disk Electrode Using Pt Supported on High-Area Carbons. J. Electrochem. Soc. 1998, 145 (11), 3713-3720.

(9). Okpalugo, T. I. T.; Papakonstantinou, P.; Murphy, H.; McLaughlin, J.; Brown, N. M. D., High resolution XPS characterization of chemical functionalised MWCNTs and SWCNTs. Carbon 2005, 43 (1), 153-161.

(10). Tavakkoli, M.; Kallio, T.; Reynaud, O.; Nasibulin, A. G.; Sainio, J.; Jiang, H.; Kauppinen, E. I.; Laasonen, K., Maghemite nanoparticles decorated on carbon nanotubes as efficient electrocatalysts for the oxygen evolution reaction. J. Mater. Chem. A 2016, 4 (14), 5216-5222.

(11). Lefrou, C.; Cornut, R., Analytical Expressions for Quantitative Scanning Electrochemical Microscopy (SECM). ChemPhysChem 2010, 11 (3), 547-556.

(12). Ho Kim, B.; Reon Kim, B.; Seo, Y. G., A Study on Adsorption Equilibrium for Oxygen and Nitrogen into Carbon Nanotubes. Adsorption 2005, 11 (1), 207-212.

(13). Toikkanen, O.; Lähteenmäki, M.; Moisio, T.; Forssell, P.; Partanen, R.; Murtomäki, L., Study of Oxygen Transfer across Milk Proteins at an Air-Water Interface with Scanning Electrochemical Microscopy. J. Agric. Food. Chem. 2014, 62 (10), 2284-2288.

(14). Slevin, C. J.; Ryley, S.; Walton, D. J.; Unwin, P. R., A New Approach for Measuring the Effect of a Monolayer on Molecular Transfer across an Air/Water Interface Using Scanning Electrochemical Microscopy. Langmuir 1998, 14 (19), 5331-5334. 
(26) Chen, Z.; Chen, X.-D.; Wang, H.; Li, X.; Lin, L.; Chen, K.; Ci, H.; Wu, X.; Zhang, Y.; Zhang, Y.; Liu, Z. One-Step Growth of Graphene/Carbon Nanotube Hybrid Films on Soda-Lime Glass for Transparent Conducting Applications. Adv. Electron. Mater. 2017, 3, No. 1700212 .

(27) Lin, C.-C.; Lin, Y.-W. Synthesis of Carbon Nanotube/ Graphene Composites by One-Step Chemical Vapor Deposition for Electrodes of Electrochemical Capacitors. J. Nanomater. 2015, 2015, No. 741928

(28) Maarouf, A. A.; Kasry, A.; Chandra, B.; Martyna, G. J. A graphene-carbon nanotube hybrid material for photovoltaic applications. Carbon 2016, 102, 74-80.

(29) Cheng, Q.; Tang, J.; Ma, J.; Zhang, H.; Shinya, N.; Qin, L.-C. Graphene and carbon nanotube composite electrodes for supercapacitors with ultra-high energy density. Phys. Chem. Chem. Phys. 2011, 13, 17615-17624.

(30) Yu, D.; Dai, L. Self-Assembled Graphene/Carbon Nanotube Hybrid Films for Supercapacitors. J. Phys. Chem. Lett. 2010, 1, 467470.

(31) You, B.; Wang, L.; Yao, L.; Yang, J. Three dimensional Ndoped graphene-CNT networks for supercapacitor. Chem. Commun. 2013, 49, 5016-5018.

(32) Dong, X.; Li, B.; Wei, A.; Cao, X.; Chan-Park, M. B.; Zhang, H.; Li, L.-J.; Huang, W.; Chen, P. One-step growth of graphene-carbon nanotube hybrid materials by chemical vapor deposition. Carbon 2011, 49, 2944-2949.

(33) Li, H.-F.; Wu, F.; Wang, C.; Zhang, P.-X.; Hu, H.-Y.; Xie, N.; Pan, M.; Zeng, Z.; Deng, S.; Wu, M. H.; Vinodgopal, K.; Dai, G.-P. One-Step Chemical Vapor Deposition Synthesis of 3D N-doped Carbon Nanotube/N-doped Graphene Hybrid Material on Nickel Foam. Nanomaterials 2018, 8, No. 700 .

(34) Lobiak, E. V.; Bulusheva, L. G.; Fedorovskaya, E. O.; Shubin, Y. V.; Plyusnin, P. E.; Lonchambon, P.; Senkovskiy, B. V.; Ismagilov, Z. R.; Flahaut, E.; Okotrub, A. V. One-step chemical vapor deposition synthesis and supercapacitor performance of nitrogen-doped porous carbon-carbon nanotube hybrids. Beilstein J. Nanotechnol. 2017, 8, 2669-2679.

(35) Liao, Y.; Mustonen, K.; Tulić, S.; Skákalová, V.; Khan, S. A.; Laiho, P.; Zhang, Q.; Li, C.; Monazam, M. R. A.; Kotakoski, J.; Lipsanen, H.; Kauppinen, E. I. Enhanced Tunneling in a Hybrid of Single-Walled Carbon Nanotubes and Graphene. ACS Nano 2019, 13, $11522-11529$.

(36) Kishor, K.; Saha, S.; Sivakumar, S.; Pala, R. G. S. Enhanced Water Oxidation Activity of the Cobalt(II,III) Oxide Electrocatalyst on an Earth-Abundant-Metal-Interlayered Hybrid Porous Carbon Support. ChemElectroChem 2016, 3, 1899-1907.

(37) Koza, J. A.; He, Z.; Miller, A. S.; Switzer, J. A. Electrodeposition of Crystalline $\mathrm{Co}_{3} \mathrm{O}_{4}-\mathrm{A}$ Catalyst for the Oxygen Evolution Reaction. Chem. Mater. 2012, 24, 3567-3573.

(38) Gorlin, Y.; Chung, C.-J.; Benck, J. D.; Nordlund, D.; Seitz, L.; Weng, T.-C.; Sokaras, D.; Clemens, B. M.; Jaramillo, T. F. Understanding Interactions between Manganese Oxide and Gold That Lead to Enhanced Activity for Electrocatalytic Water Oxidation. J. Am. Chem. Soc. 2014, 136, 4920-4926.

(39) Seitz, L. C.; Hersbach, T. J. P.; Nordlund, D.; Jaramillo, T. F. Enhancement Effect of Noble Metals on Manganese Oxide for the Oxygen Evolution Reaction. J. Phys. Chem. Lett. 2015, 6, 4178-4183.

(40) Yeo, B. S.; Bell, A. T. Enhanced Activity of Gold-Supported Cobalt Oxide for the Electrochemical Evolution of Oxygen. J. Am. Chem. Soc. 2011, 133, 5587-5593.

(41) Yeo, B. S.; Bell, A. T. In Situ Raman Study of Nickel Oxide and Gold-Supported Nickel Oxide Catalysts for the Electrochemical Evolution of Oxygen. J. Phys. Chem. C 2012, 116, 8394-8400.

(42) Zou, S.; Burke, M. S.; Kast, M. G.; Fan, J.; Danilovic, N.; Boettcher, S. W. Fe (Oxy)hydroxide Oxygen Evolution Reaction Electrocatalysis: Intrinsic Activity and the Roles of Electrical Conductivity, Substrate, and Dissolution. Chem. Mater. 2015, 27, 8011-8020.
(43) Ng, J. W. D.; García-Melchor, M.; Bajdich, M.; Chakthranont, P.; Kirk, C.; Vojvodic, A.; Jaramillo, T. F. Gold-supported ceriumdoped $\mathrm{NiOx}$ catalysts for water oxidation. Nat. Energy 2016, 1, No. 16053.

(44) Sayeed, M. A.; Herd, T.; O'Mullane, A. P. Direct electrochemical formation of nanostructured amorphous $\mathrm{Co}(\mathrm{OH}) 2$ on gold electrodes with enhanced activity for the oxygen evolution reaction. $J$. Mater. Chem. A 2016, 4, 991-999.

(45) Burke, M. S.; Kast, M. G.; Trotochaud, L.; Smith, A. M.; Boettcher, S. W. Cobalt-Iron (Oxy)hydroxide Oxygen Evolution Electrocatalysts: The Role of Structure and Composition on Activity, Stability, and Mechanism. J. Am. Chem. Soc. 2015, 137, 3638-3648.

(46) Chaudhari, N. K.; Jin, H.; Kim, B.; Lee, K. Nanostructured materials on $3 \mathrm{D}$ nickel foam as electrocatalysts for water splitting. Nanoscale 2017, 9, 12231-12247.

(47) Chen, Y.; Ji, S.; Chen, C.; Peng, Q.; Wang, D.; Li, Y. SingleAtom Catalysts: Synthetic Strategies and Electrochemical Applications. Joule 2018, 2, 1242-1264.

(48) Gawande, M. B.; Fornasiero, P.; Zbořil, R. Carbon-Based Single-Atom Catalysts for Advanced Applications. ACS Catal. 2020, 10, 2231-2259.

(49) Fei, H.; Dong, J.; Chen, D.; Hu, T.; Duan, X.; Shakir, I.; Huang, Y.; Duan, X. Single atom electrocatalysts supported on graphene or graphene-like carbons. Chem. Soc. Rev. 2019, 48, 5207-5241.

(50) Flahaut, E.; Bacsa, R.; Peigney, A.; Laurent, C. Gram-scale CCVD synthesis of double-walled carbon nanotubes. Chem. Commun. 2003, 1442-1443.

(51) Bortolamiol, T.; Lukanov, P.; Galibert, A.-M.; Soula, B.; Lonchambon, P.; Datas, L.; Flahaut, E. Double-walled carbon nanotubes: Quantitative purification assessment, balance between purification and degradation and solution filling as an evidence of opening. Carbon 2014, 78, 79-90.

(52) Weibel, A.; Mesguich, D.; Chevallier, G.; Flahaut, E.; Laurent, C. Fast and easy preparation of few-layered-graphene/magnesia powders for strong, hard and electrically conducting composites. Carbon 2018, 136, 270-279.

(53) Flahaut, E.; Peigney, A.; Bacsa, W. S.; Bacsa, R. R.; Laurent, C. CCVD synthesis of carbon nanotubes from $(\mathrm{Mg}, \mathrm{Co}, \mathrm{Mo}) \mathrm{O}$ catalysts: influence of the proportions of cobalt and molybdenum. J. Mater. Chem. 2004, 14, 646-653.

(54) Inani, H.; Mustonen, K.; Markevich, A.; Ding, E.-X.; Tripathi, M.; Hussain, A.; Mangler, C.; Kauppinen, E. I.; Susi, T.; Kotakoski, J. Silicon Substitution in Nanotubes and Graphene via Intermittent Vacancies. J. Phys. Chem. C 2019, 123, 13136-13140.

(55) Mustonen, K.; Markevich, A.; Tripathi, M.; Inani, H.; Ding, E.X.; Hussain, A.; Mangler, C.; Kauppinen, E. I.; Kotakoski, J.; Susi, T. Electron-Beam Manipulation of Silicon Impurities in Single-Walled Carbon Nanotubes. Adv. Funct. Mater. 2019, 29, No. 1901327.

(56) Ortalan, V.; Uzun, A.; Gates, B. C.; Browning, N. D. Direct imaging of single metal atoms and clusters in the pores of dealuminated HY zeolite. Nat. Nanotechnol. 2010, 5, 506-510.

(57) Nellist, P. D.; Pennycook, S. J. Direct Imaging of the Atomic Configuration of Ultradispersed Catalysts. Science 1996, 274, 413415.

(58) Jiang, H.; Ruokolainen, J.; Young, N.; Oikawa, T.; Nasibulin, A. G.; Kirkland, A.; Kauppinen, E. I. Performance and early applications of a versatile double aberration-corrected JEOL-2200FS FEG TEM/ STEM at Aalto University. Micron 2012, 43, 545-550.

(59) Arenal, R.; March, K.; Ewels, C. P.; Rocquefelte, X.; Kociak, M.; Loiseau, A.; Stéphan, O. Atomic Configuration of Nitrogen-Doped Single-Walled Carbon Nanotubes. Nano Lett. 2014, 14, 5509-5516.

(60) Willke, P.; Amani, J. A.; Sinterhauf, A.; Thakur, S.; Kotzott, T.; Druga, T.; Weikert, S.; Maiti, K.; Hofsäss, H.; Wenderoth, M. Doping of Graphene by Low-Energy Ion Beam Implantation: Structural, Electronic, and Transport Properties. Nano Lett. 2015, 15, 51105115.

(61) Egerton, R. F. Beam-Induced Motion of Adatoms in the Transmission Electron Microscope. Microsc. Microanal. 2013, 19, 479-486. 
(62) Dresselhaus, M. S.; Dresselhaus, G.; Saito, R.; Jorio, A. Raman spectroscopy of carbon nanotubes. Phys. Rep. 2005, 409, 47-99.

(63) Dresselhaus, M. S.; Jorio, A.; Hofmann, M.; Dresselhaus, G.; Saito, R. Perspectives on Carbon Nanotubes and Graphene Raman Spectroscopy. Nano Lett. 2010, 10, 751-758.

(64) Dresselhaus, M. S.; Jorio, A.; Filho, A. G. S.; Saito, R. Defect characterization in graphene and carbon nanotubes using Raman spectroscopy. Philos. Trans. R. Soc., A 2010, 368, 5355-5377.

(65) Donohue, M. D.; Aranovich, G. L. Classification of Gibbs adsorption isotherms. Adv. Colloid Interface Sci. 1998, 76-77, 137152.

(66) Alothman, Z. A. A Review: Fundamental Aspects of Silicate Mesoporous Materials. Materials 2012, 5, 2874-2902.

(67) Huang, P.; Li, H.; Huang, X.; Chen, D. MultiheteroatomDoped Porous Carbon Catalyst for Oxygen Reduction Reaction Prepared using 3D Network of ZIF-8/Polymeric Nanofiber as a Facile-Doping Template. ACS Appl. Mater. Interfaces 2017, 9, 2108321088.

(68) Sharma, M.; Jang, J.-H.; Shin, D. Y.; Kwon, J. A.; Lim, D.-H.; Choi, D.; Sung, H.; Jang, J.; Lee, S.-Y.; Lee, K. Y.; Park, H.-Y.; Jung, N.; Yoo, S. J. Work function-tailored graphene via transition metal encapsulation as a highly active and durable catalyst for the oxygen reduction reaction. Energy Environ. Sci. 2019, 12, 2200-2211.

(69) Qiu, K.; Chai, G.; Jiang, C.; Ling, M.; Tang, J.; Guo, Z. Highly Efficient Oxygen Reduction Catalysts by Rational Synthesis of Nanoconfined Maghemite in a Nitrogen-Doped Graphene Framework. ACS Catal. 2016, 6, 3558-3568.

(70) Chen, Y.; Ji, S.; Zhao, S.; Chen, W.; Dong, J.; Cheong, W.-C.; Shen, R.; Wen, X.; Zheng, L.; Rykov, A. I.; Cai, S.; Tang, H.; Zhuang, Z.; Chen, C.; Peng, Q.; Wang, D.; Li, Y. Enhanced oxygen reduction with single-atomic-site iron catalysts for a zinc-air battery and hydrogen-air fuel cell. Nat. Commun. 2018, 9, No. 5422.

(71) Yan, X.; Yao, Y.; Chen, Y. Highly Active and Stable Fe-N-C Oxygen Reduction Electrocatalysts Derived from Electrospinning and In Situ Pyrolysis. Nanoscale Res. Lett. 2018, 13, No. 218.

(72) Sharifi, T.; Gracia-Espino, E.; Chen, A.; Hu, G.; Wågberg, T. Oxygen Reduction Reactions on Single- or Few-Atom Discrete Active Sites for Heterogeneous Catalysis. Adv. Energy Mater. 2020, 101902084

(73) Zhou, W.; Huang, D.-D.; Wu, Y.-P.; Zhao, J.; Wu, T.; Zhang, J.; Li, D.-S.; Sun, C.; Feng, P.; Bu, X. Stable Hierarchical BimetalOrganic Nanostructures as HighPerformance Electrocatalysts for the Oxygen Evolution Reaction. Angew. Chem., Int. Ed. 2019, 58, 42274231

(74) Tavakkoli, M.; Nosek, M.; Sainio, J.; Davodi, F.; Kallio, T.; Joensuu, P. M.; Laasonen, K. Functionalized Carbon Nanotubes with $\mathrm{Ni}(\mathrm{II})$ Bipyridine Complexes as Efficient Catalysts for the Alkaline Oxygen Evolution Reaction. ACS Catal. 2017, 7, 8033-8041.

(75) Kauffman, D. R.; Alfonso, D.; Tafen, D. N.; Lekse, J.; Wang, C.; Deng, X.; Lee, J.; Jang, H.; Lee, J.; Kumar, S.; Matranga, C. Electrocatalytic Oxygen Evolution with an Atomically Precise Nickel Catalyst. ACS Catal. 2016, 6, 1225-1234.

(76) Gao, M.; Sheng, W.; Zhuang, Z.; Fang, Q.; Gu, S.; Jiang, J.; Yan, Y. Efficient Water Oxidation Using Nanostructured $\alpha$-NickelHydroxide as an Electrocatalyst. J. Am. Chem. Soc. 2014, 136, 70777084

(77) Tavakkoli, M.; Kallio, T.; Reynaud, O.; Nasibulin, A. G.; Sainio, J.; Jiang, H.; Kauppinen, E. I.; Laasonen, K. Maghemite nanoparticles decorated on carbon nanotubes as efficient electrocatalysts for the oxygen evolution reaction. J. Mater. Chem. A 2016, 4, 5216-5222.

(78) Lei, C.; Lyu, S.; Si, J.; Yang, B.; Li, Z.; Lei, L.; Wen, Z.; Wu, G.; Hou, Y. Nanostructured Carbon Based Heterogeneous Electrocatalysts for Oxygen Evolution Reaction in Alkaline Media. Chem CatChem 2019, 11, 5855-5874.

(79) Browne, M. P.; Mills, A. Determining the importance of the electrode support and fabrication method during the initial screening process of an active catalyst for the oxygen evolution reaction. J. Mater. Chem. A 2018, 6, 14162-14169.
(80) Wang, L.; Stoerzinger, K. A.; Chang, L.; Zhao, J.; Li, Y.; Tang, C. S.; Yin, X.; Bowden, M. E.; Yang, Z.; Guo, H.; You, L.; Guo, R.; Wang, J.; Ibrahim, K.; Chen, J.; Rusydi, A.; Wang, J.; Chambers, S. A.; $\mathrm{Du}, \mathrm{Y}$. Tuning Bifunctional Oxygen Electrocatalysts by Changing the A-Site Rare-Earth Element in Perovskite Nickelates. Adv. Funct. Mater. 2018, 28, No. 1803712.

(81) Kirsanova, M. A.; Okatenko, V. D.; Aksyonov, D. A.; Forslund, R. P.; Mefford, J. T.; Stevenson, K. J.; Abakumov, A. M. Bifunctional OER/ORR catalytic activity in the tetrahedral YBaCo4O7.3 oxide. J. Mater. Chem. A 2019, 7, 330-341.

(82) Hu, X.; Huang, T.; Tang, Y.; Fu, G.; Lee, J.-M. ThreeDimensional Graphene-Supported Ni3Fe/Co9S8 Composites: Rational Design and Active for Oxygen Reversible Electrocatalysis. ACS Appl. Mater. Interfaces 2019, 11, 4028-4036.

(83) Yang, H. B.; Miao, J.; Hung, S.-F.; Chen, J.; Tao, H. B.; Wang, X.; Zhang, L.; Chen, R.; Gao, J.; Chen, H. M.; Dai, L.; Liu, B. Identification of catalytic sites for oxygen reduction and oxygen evolution in $\mathrm{N}$-doped graphene materials: Development of highly efficient metal-free bifunctional electrocatalyst. Sci. Adv. 2016, 2, No. e1501122.

(84) Xu, N.; Zhang, Y.; Zhang, T.; Liu, Y.; Qiao, J. Efficient quantum dots anchored nanocomposite for highly active ORR/OER electrocatalyst of advanced metal-air batteries. Nano Energy 2019, 57, 176185 .

(85) Bu, Y.; Nam, G.; Kim, S.; Choi, K.; Zhong, Q.; Lee, J.; Qin, Y.; Cho, J.; Kim, G. A Tailored Bifunctional Electrocatalyst: Boosting Oxygen Reduction/Evolution Catalysis via Electron Transfer Between N-Doped Graphene and Perovskite Oxides. Small 2018, 14, No. 1802767.

(86) Biesinger, M. C.; Payne, B. P.; Grosvenor, A. P.; Lau, L. W. M.; Gerson, A. R.; Smart, R. S. C. Resolving surface chemical states in XPS analysis of first row transition metals, oxides and hydroxides: $\mathrm{Cr}$, Mn, Fe, Co and Ni. Appl. Surf. Sci. 2011, 257, 2717-2730.

(87) Baltrusaitis, J.; Mendoza-Sanchez, B.; Fernandez, V.; Veenstra, R.; Dukstiene, N.; Roberts, A.; Fairley, N. Generalized molybdenum oxide surface chemical state XPS determination via informed amorphous sample model. Appl. Surf. Sci. 2015, 326, 151-161.

(88) Povey, A. F.; Metcalfe, A. A. The anodic dissolution of molybdenum in alkaline solutions - X-ray photoelectron spectroscopic studies. J. Electroanal. Chem. Interfacial Electrochem. 1977, 84, $73-81$.

(89) Susi, T.; Pichler, T.; Ayala, P. X-ray photoelectron spectroscopy of graphitic carbon nanomaterials doped with heteroatoms. Beilstein J. Nanotechnol. 2015, 6, 177-192.

(90) Chen, S.; Bi, J.; Zhao, Y.; Yang, L.; Zhang, C.; Ma, Y.; Wu, Q.; Wang, X.; Hu, Z. Nitrogen-Doped Carbon Nanocages as Efficient Metal-Free Electrocatalysts for Oxygen Reduction Reaction. Adv. Mater. 2012, 24, 5593-5597.

(91) Lin, T.-E.; Cortés-Salazar, F.; Lesch, A.; Qiao, L.; Bondarenko, A.; Girault, H. H. Multiple scanning electrochemical microscopy mapping of tyrosinase in micro-contact printed fruit samples on polyvinylidene fluoride membrane. Electrochim. Acta 2015, 179, 5764.

(92) Toikkanen, O.; Lähteenmäki, M.; Moisio, T.; Forssell, P.; Partanen, R.; Murtomäki, L. Study of Oxygen Transfer across Milk Proteins at an Air-Water Interface with Scanning Electrochemical Microscopy. J. Agric. Food. Chem. 2014, 62, 2284-2288.

(93) Slevin, C. J.; Ryley, S.; Walton, D. J.; Unwin, P. R. A New Approach for Measuring the Effect of a Monolayer on Molecular Transfer across an Air/Water Interface Using Scanning Electrochemical Microscopy. Langmuir 1998, 14, 5331-5334.

(94) Cortés-Salazar, F.; Deng, H.; Peljo, P.; Pereira, C. M.; Kontturi, K.; Girault, H. H. Parylene C coated microelectrodes for scanning electrochemical microscopy. Electrochim. Acta 2013, 110, 22-29.

(95) Haensch, M.; Balboa, L.; Graf, M.; Silva Olaya, A. R.; Weissmüller, J.; Wittstock, G. Mass Transport in Porous Electrodes Studied by Scanning Electrochemical Microscopy: Example of Nanoporous Gold. ChemElectroChem 2019, 6, 3160-3166. 
(96) Snook, G. A.; Duffy, N. W.; Pandolfo, A. G. Detection of Oxygen Evolution from Nickel Hydroxide Electrodes Using Scanning

Electrochemical Microscopy. J. Electrochem. Soc. 2008, 155, A262-

A267. 